\title{
Real-Time In Situ Measurements of Industrial Hazardous Gas Concentrations and Their Emission Gross
}

\author{
F.Z. Dong et al. ${ }^{*}$ \\ Anhui Institute of Optics and Fine Mechanics, \\ Chinese Academy of Sciences, Science Island, Hefei, \\ P. R. China
}

\section{Introduction}

Over the past few decades environmental protection has been of greatly worldwide concerns due to the fact of global warming and air quality deterioration particularly in the fast developing countries like China and India (Platt, 1980; Edner, 1991; Sigrist, 1995; Culshaw, 1998; Fried, 1998; Linnerud, 1998; Weibring, 1998; Nelson, 2002; Liu, 2002; Christian, 2003 \& 2004; Taslakov, 2006; de Gouw, 2007; Karl, 2007 \& 2009; http://www.cnemc.cn). These have resulted in large demands and tremendous efforts for new technology developments to monitor and control industrial gas pollution (Lindinger, 1998; Dong, 2005; Kan, 2006 \& 2007; Wang Y.J., 2009; Wang F., 2010; Xia, 2010; Zhang, 2011). $\mathrm{CO}_{2}, \mathrm{CO}, \mathrm{NH}_{3}, \mathrm{H}_{2} \mathrm{~S}, \mathrm{HF}, \mathrm{HCI}$, and volatile organic compounds (VOCs) are very important gases generated in many industrial processes; therefore to implement on-line monitoring of these industrial emitted gases is a key factor for industrial process control. Furthermore if one can simultaneously measure the gas flow path-averaged velocity and gas concentrations in a smokestack, all the industrial emissions from the targeted smokestack would be realtime obtained. This could be much beneficial to the administrative implementation of global environmental protection policy on reduction of gas pollution and environmental management.

Tunable diode laser absorption spectroscopy (TDLAS) is a kind of technology with advantages of high sensitivity, high selectivity and fast responsibility. It has been widely used in the applications of green-house measurements (Feher, 1995; Nadezhdinskii, 1999; Kan, 2006), hazardous gas leakage detection (May, 1989; Uehara, 1992; Iseki, 2000 \& 2004), industry process control (Linnerud, 1998; Deguchi,2002) and combustion gas measurements (Zhou, 2005; Rieker, 2009). Proton transfer reaction-mass spectrometry (PTR-MS) is a relatively new technology firstly developed at the University of Innsbruck, Austria, in the 1990s (Hansel, 1995). PTR-MS has been found being an extremely powerful and promising technology for online detection of VOCs at trace level (Smith, 2005; Jordan, 2009). Optical flow sensor (OFS-2000) based on the concept of optical scintillation to measure airflow velocity (Wang T.I., 1981;

\footnotetext{
* W.Q. Liu, Y.N. Chu, J.Q. Li, Z.R. Zhang, Y. Wang, T. Pang, B. Wu, G.J. Tu, H. Xia, Y. Yang,

C.Y.Shen, Y.J. Wang, Z.B. Ni and J.G. Liu

Anhui Institute of Optics and Fine Mechanics, Chinese Academy of Sciences, Science Island, Hefei, P. R. China.
} 
http://www.opticalscientific.com), which is first developed by Optical Scientific INC., has been widely used in the market. OFS-2000 utilizes the high frequency signal of optical scintillation cross-correlation (OSCC) which is from the fluctuations of temperature or refractive index. However, OFS-2000 is not applicable when the temperature fluctuation within the measurement area is small or even ignorable. Recently we have developed a new kind of optical flow sensor which is based on the low frequency signal of OSCC resulting from the particle concentration fluctuations. Therefore the newly developed optical flow sensor could also measure the particle concentration in the stack.

The content of this chapter will first briefly describe the operational principles based on TDLAS, PTR-MS and OSCC technologies for industrial pollution on-line monitoring. Then the instruments developed by our group to measure the emission gross will be introduced. In the third section some experimental results from the field test will be presented. Finally the discussions and conclusions will be given.

\section{Basic operational principles of the instruments}

\subsection{TDLAS technique}

For detecting low concentration gases at atmospheric pressure with TDLAS technique, twotone modulations and harmonic detection method are commonly adopted. The diode laser is modulated with the homemade current and temperature controllers to the wavelength of $1.567 \mu \mathrm{m}$ which precisely locates at the selected absorption line central of target gas CO. The laser wavelength is scanned through the selected absorption line by a saw-tooth signal at low frequency of $147 \mathrm{~Hz}$ and simultaneously modulated by a sinusoidal signal at frequency of $20 \mathrm{KHz}$. The modulated laser beam is divided into two parts with a $1 \times 2$ fiber splitter. One arm $(20 \%)$ is used to go through a $10 \mathrm{~cm}$ calibration cell as a reference signal, while the other arm $(80 \%)$ is used to measure the flue gas concentrations. Two transmitted laser beams are collimated and then collected by two coincident InGaAs photodiodes after passing through absorption gases, respectively. These two current signals are then transmitted into the digital control module (DCM) to gain the harmonic signals. At last, these signals are sent to computer for processing and harmonic signal detection technique is used for calculation of the target gas concentration. The schematic diagram of the online TDLAS experimental setup is shown in Figure 1.

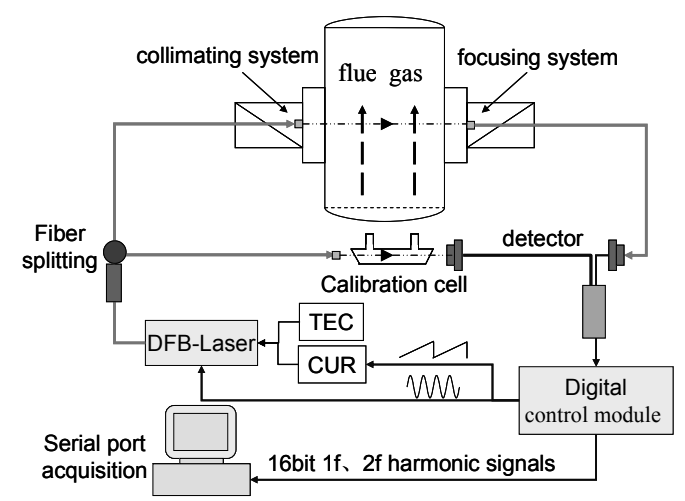

TEC: thermo-electronic cooler; CUR: current controller.

Fig. 1. On-line experimental apparatus for TDLAS system. 
When the light passes through flue gases, lots of factors can reduce the light intensity, like dust scattering and absorption in transmission medium. Considering about the intensity reduction by gas absorption, Beer-Lambert law is used. The responses can be described as:

$$
\frac{I}{I_{0}}=\exp (-k L)
$$

Where $I$ represents the light intensity after passing the absorption gas, and $I_{0}$ represents the light intensity before passing the absorption gas, $k$ is a reducing coefficient and $L$ denotes the path length. When the gas absorption is very small, i.e., $k L \leq 0.05$ (Reid, 1981; Cassidy, 1982), equation (1) can be simplified as:

$$
\frac{I}{I_{0}}=1-k L=1-\sigma(v) C L
$$

Where $\sigma(\nu)$ is the absorption coefficient. C and L stand for gas concentration and total optical length. The intensity of second harmonic (2f) signal can be expressed as below (Reid, 1981; Kan, 2006):

$$
\mathrm{I}_{2 \mathrm{f}} \propto \mathrm{I}_{0} \mathrm{\sigma}_{0} \mathrm{CL}
$$

Where $I_{2 f}$ is proportional to the incident laser intensity $I_{0}$ and absorption coefficient $\sigma_{0}$ at the central wavelength of the absorption line. Nonlinear least square multiplication method is used to fit the $2 \mathrm{f}$ signal with reference signal for gaining the calibration coefficient a (Kan, 2007):

$$
\mathrm{I}_{01} \mathrm{C}_{\mathrm{Mea}} \mathrm{L}_{01}=\mathrm{a} \mathrm{I}_{02} \mathrm{C}_{\text {Ref }} \mathrm{L}_{02}
$$

Where $\mathrm{C}_{\mathrm{Mea}}$ and $\mathrm{C}_{\mathrm{Ref}}$ are the concentrations of the target gas to be measured and reference gas in the calibration cell, respectively; $\mathrm{I}_{01}, \mathrm{I}_{02}$ are the initial intensities of the two laser beams; $\mathrm{L}_{01}$ and $\mathrm{L}_{02}$ are the length of measurement optical path and the calibration cell, respectively. From equation (4), we could obtain:

$$
\mathrm{C}_{\mathrm{Mea}}=\mathrm{a} \mathrm{I} \mathrm{I}_{02} \mathrm{C}_{\mathrm{Ref}} \mathrm{L}_{02} / \mathrm{I}_{01} \mathrm{~L}_{01}
$$

While a saw-tooth current is added on the DFB diode laser, the light wavelength will scan in a certain region, then the gas can be detected if there is a gas absorption line in that region. For detection of high concentration gas, direct absorption method is often used. This method is very simple but the sensitivity is suffered from massive random noises, which is mainly the 1 /f noise from the diode laser and the photon detector. However, for low concentration gas detection, in order to eliminate serious noises in the system and enhance the sensitivity, another high frequency sine modulation current is added on the ramp signal. The gas absorption signal can be then achieved with high SNR by monitoring the second harmonic signal of absorption in a very narrow frequency band using a lock-in amplifier (LIA). If one does not pay enough attention, there will be so many factors like dust scattering and imperfect performance of laser source itself affecting the measurement accuracy. In addition, for a practical TDLAS system there are always various noises inevitably existed resulting from predictable or unpredictable sources. For instance, quickly changing random noise affects the sensitivity, and slow signal distortion limits long-term stability of the system 
because of its large amplitude. It has been reported that a lot of reasons like wavelength drifts and etalon fringe structure change because of thermal effect can result to slow $2 \mathrm{f}$ signal distortion (Werle, 1996). Few technologies had been reported to eliminate those distortions like rapid background subtraction (Cassidy \& Reid, 1982) and digital signal processing (Reid, 1980), but there are some limits of those ideas when the condition is changed. In fact it is inconvenient to get the background structure in real time for a in situ gas analytical system, particularly when the interference or distortion has similar frequency with the absorption signal in which the digital method could not work well.

Over the past decades many advanced digital signal processing methods for TDLAS system development have been reported. Peter Werle et al (Werle, 1996 \& 2004) have demonstrated a method to avoid the effects of noise disturbances and laser wavelength drifts during integration and background changes. To decrease high frequency noise and enhance the stability of a practical TDLAS system, except of optimizing hardware, advanced signal processing algorithm is also needed and have been explored by our group (Xia, 2010 ; Zhang, 2010). One of the novel features in our research is the use of digital signal processing for harmonic signals for which the laser output wavelength can be locked at the absorption line center and fit with reference harmonic signal by utilizing nonlinear least squares routine. The signal-correlation must be computed rapidly. The Fast Fourier Transform (FFT), low-pass filter and Inverse Fast Fourier Transform (IFFT) algorithm are adopted. The correlation version for an $\mathrm{N}$-point spectrum signal is:

$$
C(S, S)_{i}=S^{\text {Ref }} \otimes S^{\text {Mea }}=\sum_{j=0}^{N} S_{j}^{\text {Ref }} \cdot S_{i+j}^{\text {Mea }}
$$

Where SRef and SMea are the reference and measurement signals acquired during calibration and subsequent measured harmonic signal, respectively with the lag represented by $i$. Using the discrete FFT the correlation signal $C(S, S)_{i}$ can be written as:

$$
C(S, S)_{i}=F_{j}\left(S^{R e f}\right) F_{j}^{*}\left(S^{M e a}\right)
$$

where $F_{j}(S)$ stands for the FFT of $S$. The low pass filter is used to remove high frequency noise simultaneously in the process. The IFFT result between measured signal and reference signal in the above process is used to get the correlation data. Then using the peak-find routine the drift MAX-value position is obtained. At last, the corrected signal position is translated getting the proper data to decrease effects caused by the temperature, current and other external uncertain factors.

\subsection{PTR-MS}

Proton transfer reaction mass spectrometry (PTR-MS) was first developed at the Institute of Ion Physics of Innsbruck University in the 1990's. Nowadays PTR-MS has been a welldeveloped and commercially available technique for the on-line monitoring of trace volatile organic compounds (VOCs) down to parts per trillion by volume (ppt) level. PTR-MS has some advantages such as rapid response, soft chemical ionization (CI), absolute quantification and high sensitivity. In general, a standard PTR-MS instrument consists of external ion source, drift tube and mass analysis detection system. Fig. 2 illustrates the basic composition of the PTR-MS instrument constructed in our laboratory using a quadrupole mass spectrometer as the detection system. 


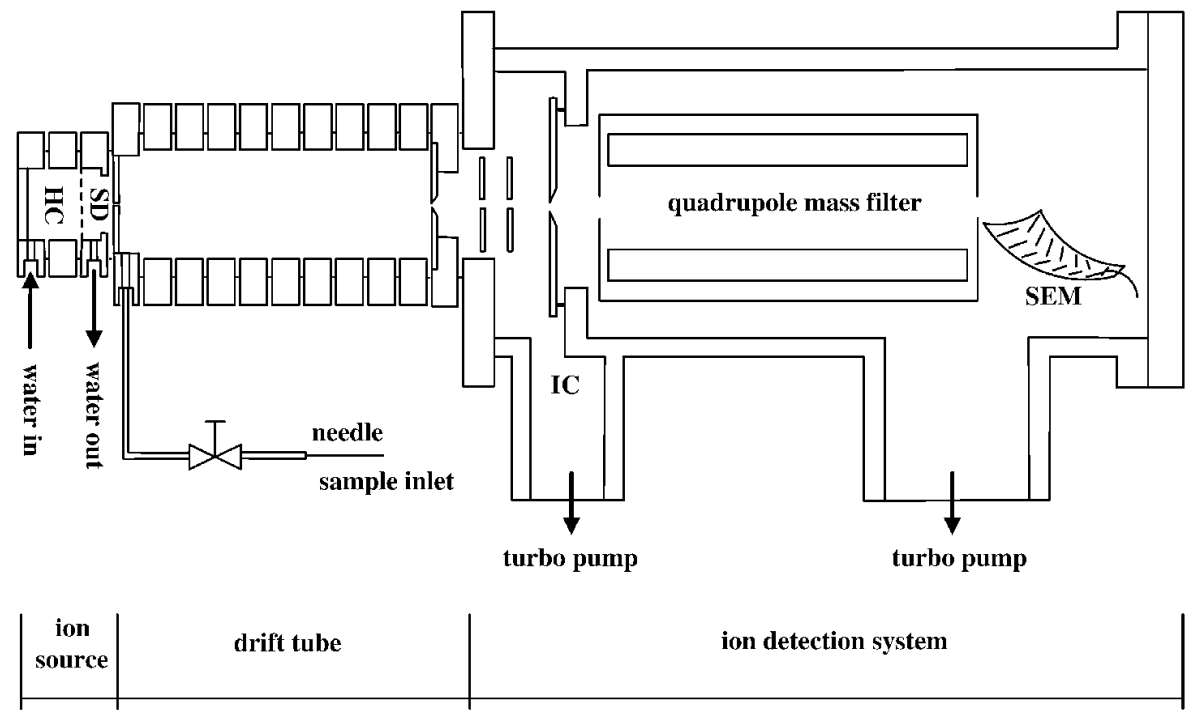

Fig. 2. Schematic diagram of the PTR-MS instrument that contains a hollow cathode (HC), a source drift (SD) region, an intermediate chamber(IC) and a secondary electron multiplier (SEM).

Perhaps the most remarkable feature of PTR-MS is the special chemical ionization (CI) mode through well-controlled proton transfer reaction, in which the neutral molecule $\mathrm{M}$ may be converted to a nearly unique protonated molecular ion $\mathrm{MH}^{+}$. This ionization mode is completely different from the traditional MS where electron impact (EI) with energy of $70 \mathrm{eV}$ is often used to ionize chemicals like VOCs. Although the EI source has been widely used with the commercial MS instruments most coupled with a variety of chromatography techniques, these MS platforms have a major deficiency: in the course of ionization the molecule will be dissociated to many fragment ions. This extensive fragmentation may result in complex mass spectra pertain especially when a mixture is measured. If a chromatographic separation method is not used prior to MS, then the resulting mass spectra from EI may be so complicated that identification and quantification of the compounds can be very difficult. In PTR-MS instrument, the hollow cathode discharge is served as a typical ion source [Blake, 2009], although plane electrode dc discharge [Inomata, 2006] and radioactive ionization sources [Hanson, 2003] recently have been reported. All of the ion sources are used to generate clean and intense primary reagent ions like $\mathrm{H}_{3} \mathrm{O}^{+}$. Water vapor is a regular gas in the hollow cathode discharge where $\mathrm{H}_{2} \mathrm{O}$ molecule can be ionized according to the following ways (Hansel, A.,1995).

$$
\begin{array}{r}
e+\mathrm{H}_{2} \mathrm{O} \rightarrow \mathrm{H}_{2}{ }^{+}+\mathrm{O}+2 e \\
e+\mathrm{H}_{2} \mathrm{O} \rightarrow \mathrm{H}^{+}+\mathrm{OH}+2 e \\
e+\mathrm{H}_{2} \mathrm{O} \rightarrow \mathrm{O}^{++} \mathrm{H}_{2}+2 e \\
e+\mathrm{H}_{2} \mathrm{O} \rightarrow \mathrm{H}_{2} \mathrm{O}^{++} e
\end{array}
$$


The above ions are injected into a short source drift region and further react with $\mathrm{H}_{2} \mathrm{O}$ ultimately leading to the formation of $\mathrm{H}_{3} \mathrm{O}^{+}$via ion-molecule reactions:

$$
\begin{gathered}
\mathrm{H}_{2}{ }^{+}+\mathrm{H}_{2} \mathrm{O} \rightarrow \mathrm{H}_{2} \mathrm{O}^{++} \mathrm{H}_{2} \\
\rightarrow \mathrm{H}_{3} \mathrm{O}^{++} \mathrm{H} \\
\mathrm{H}^{++} \mathrm{H}_{2} \mathrm{O} \rightarrow \mathrm{H}_{2} \mathrm{O}^{++} \mathrm{H} \\
\mathrm{O}^{++} \mathrm{H}_{2} \mathrm{O} \rightarrow \mathrm{H}_{2} \mathrm{O}^{++} \mathrm{O} \\
\mathrm{OH}^{++} \mathrm{H}_{2} \mathrm{O} \rightarrow \mathrm{H}_{3} \mathrm{O}^{++} \mathrm{O} \\
\rightarrow \mathrm{H}_{2} \mathrm{O}^{+}+\mathrm{OH} \\
\mathrm{H}_{2} \mathrm{O}^{++} \mathrm{H}_{2} \mathrm{O} \rightarrow \mathrm{H}_{3} \mathrm{O}^{++} \mathrm{OH}
\end{gathered}
$$

Unfortunately, the water vapor in the source drift region can inevitably form a few of cluster ions $\mathrm{H}_{3} \mathrm{O}^{+}\left(\mathrm{H}_{2} \mathrm{O}\right)_{\mathrm{n}}$ via the three-body combination process

$$
\mathrm{H}_{3} \mathrm{O}^{+}\left(\mathrm{H}_{2} \mathrm{O}\right)_{n-1}+\mathrm{H}_{2} \mathrm{O}+\mathrm{A} \rightarrow \mathrm{H}_{3} \mathrm{O}^{+}\left(\mathrm{H}_{2} \mathrm{O}\right)_{n}+\mathrm{A} \quad(\mathrm{n} \geq 1)
$$

where $\mathrm{A}$ is a third body. In addition there are small amounts of $\mathrm{NO}^{+}$and $\mathrm{O}_{2}{ }^{+}$ions occurred due to sample air diffusion into the source region from the downstream drift tube. Thus an inlet of venturi-type has been employed on some PTR-MS systems to prevent air from entering the source drift region (Duperat, 1982; Lindinger, 1998). At last the $\mathrm{H}_{3} \mathrm{O}^{+}$ions produced in the ion source can have the purity up to $>99.5 \%$. Thus, unlike SIFT-MS technique (Smith, 2005), the mass filter of the primary ionic selection is not needed and the $\mathrm{H}_{3} \mathrm{O}^{+}$ions can be directly injected into the drift tube. In some of PTR-MS, the ion intensity of $\mathrm{H}_{3} \mathrm{O}^{+}$is available at $10^{6} \sim 10^{7}$ counts per second on a mass spectrometer installed in the vacuum chamber at the end of the drift tube. Eventually the limitation of detection of PTRMS can reach low ppt level.

Instead of $\mathrm{H}_{3} \mathrm{O}^{+}$, other primary reagent ions, such as $\mathrm{NH}_{4}{ }^{+}, \mathrm{NO}^{+}$and $\mathrm{O}_{2}{ }^{+}$, have been investigated in PTR-MS instrument (Wiche, 2005; Blake, 2006; Jordan, 2009). Because the ion chemistry for these ions is not only proton transfer reaction, the technique sometimes is called chemical ionization reaction mass spectrometry. However, the potential benefits of using these alternative reagents usually are minimal, and to our knowledge, $\mathrm{H}_{3} \mathrm{O}^{+}$is still the dominant reagent ion employed in PTR-MS research (Blake, 2009; Lindinger, 1998; de Gouw, 2007; Jin, 2007).

The drift tube consists of a number of metal rings that are equally separated from each other by insulated rings. Between the adjacent metal rings a series of resistors is connected. A high voltage power supplier produces a voltage gradient and establishes a homogeneous electric field along the axis of the ion reaction drift tube.

The primary $\mathrm{H}_{3} \mathrm{O}^{+}$ions are extracted into the ion reaction region and can react with analyte $\mathrm{M}$ in the sample air, which through the inlet is added to the upstream of the ion reaction drift tube. According to the values of proton affinity (PA) (see Table 1), the reagent ion $\mathrm{H}_{3} \mathrm{O}^{+}$ does not react with the main components in air like $\mathrm{N}_{2}, \mathrm{O}_{2}$ and $\mathrm{CO}_{2}$. In contrast, the reagent ion can undergo proton transfer reaction with $\mathrm{M}$ as long as the PA of $\mathrm{M}$ exceeds that of $\mathrm{H}_{2} \mathrm{O}$ (Lindinger, 1998). 


$$
\mathrm{M}+\mathrm{H}_{3} \mathrm{O}^{+} \rightarrow \mathrm{MH}^{+}+\mathrm{H}_{2} \mathrm{O}
$$

Thus, the ambient air can be directly introduced to achieve an on-line measurement in the PTR-MS operation. Due to the presence of electric field, in the reaction region the ion energy is closely related to the reduced-field $E / N$, where $E$ is the electric field and $N$ is the number density of gas in the drift tube. In a typical PTR-MS measurement, $E / N$ is required to set to an appropriate value normally in the range of $120 \sim 160 \mathrm{Td}\left(1 \mathrm{Td}=10^{-17} \mathrm{Vcm}^{2}\right.$ molecule- $\left.{ }^{-1}\right)$ which may restrain the formation of the water cluster ions $\mathrm{H}_{3} \mathrm{O}^{+}\left(\mathrm{H}_{2} \mathrm{O}\right)_{n}(\mathrm{n}=1-3)$ to avoid the ligand switch reaction with analyte M (Lindinger, 1998):

$$
\mathrm{H}_{3} \mathrm{O}^{+}\left(\mathrm{H}_{2} \mathrm{O}\right)_{n}+\mathrm{M} \rightarrow \mathrm{H}_{3} \mathrm{O}^{+}\left(\mathrm{H}_{2} \mathrm{O}\right)_{n-1} \mathrm{M}+\mathrm{H}_{2} \mathrm{O}
$$

However, a higher reduced-field $E / N$ can cause the collision-induced dissociation of the

\begin{tabular}{|c|c|c|c|}
\hline Compound & Molecular formula & Molecular weight & $\begin{array}{c}\text { Proton affinity( }{ }^{(\text {NIST database })} \\
\left(\mathrm{kJ} \mathrm{mol}^{-1}\right)\end{array}$ \\
\hline Helium & $\mathrm{He}$ & 4 & 177.8 \\
\hline Neon & $\mathrm{Ne}$ & 20 & 198.8 \\
\hline Argon & $\mathrm{Ar}$ & 40 & 369.2 \\
\hline Oxygen & $\mathrm{O}_{2}$ & 32 & 421 \\
\hline Nitrogen & $\mathrm{N}_{2}$ & 28 & 493.8 \\
\hline Carbon dioxide & $\mathrm{CO}_{2}$ & 44 & 540.5 \\
\hline methane & $\mathrm{CH}_{4}$ & 16 & 543.5 \\
\hline Carbon monoxide & $\mathrm{CO}$ & 28 & 594 \\
\hline Ethane & $\mathrm{C}_{2} \mathrm{H}_{6}$ & 30 & 596.3 \\
\hline Ethylene & $\mathrm{C}_{2} \mathrm{H}_{4}$ & 28 & 680.5 \\
\hline Water & $\mathrm{H}_{2} \mathrm{O}$ & 18 & 691 \\
\hline Hydrogen sulphide & $\mathrm{H}_{2} \mathrm{~S}$ & 34 & 705 \\
\hline Hydrogen cyanide & $\mathrm{HCN}$ & 27 & 712.9 \\
\hline Formic acid & $\mathrm{HCOOH}$ & 46 & 742 \\
\hline Benzene & $\mathrm{C}_{6} \mathrm{H}_{6}$ & 78 & 750.4 \\
\hline Propene & $\mathrm{C}_{3} \mathrm{H}_{6}$ & 42 & 751.6 \\
\hline Methanol & $\mathrm{CH}_{3} \mathrm{OH}$ & 32 & 754.3 \\
\hline Acetaldehyde & $\mathrm{CH}_{3} \mathrm{COH}$ & 44 & 768.5 \\
\hline Ethanol & $\mathrm{C}_{2} \mathrm{H}_{5} \mathrm{OH}$ & 46 & 776.4 \\
\hline Acetonitrile & $\mathrm{CH}_{3} \mathrm{CN}$ & 41 & 779.2 \\
\hline Acetic acid & $\mathrm{CH}_{3} \mathrm{COOH}$ & 60 & 783.7 \\
\hline Toluene & $\mathrm{C}_{7} \mathrm{H}_{8}$ & 92 & 784 \\
\hline Propanal & $\mathrm{CH}_{3} \mathrm{CH}_{2} \mathrm{COH}$ & 58 & 786 \\
\hline O-xylene & $\mathrm{C}_{8} \mathrm{H}_{10}$ & 106 & 796 \\
\hline Acetone & $\mathrm{CH}_{3} \mathrm{COCH}_{3}$ & 58 & 812 \\
\hline Isoprene & $\mathrm{CH}_{2} \mathrm{C}\left(\mathrm{CH}_{3}\right) \mathrm{CHCH}_{2}$ & 68 & 826.4 \\
\hline Ammonia & $\mathrm{NH}_{3}$ & 17 & 853.6 \\
\hline Aniline & $\mathrm{C}_{6} \mathrm{H}_{7} \mathrm{~N}$ & 93 & 882.5 \\
\hline
\end{tabular}
protonated products, thereby complicating the identification of detected analytes.

Table 1. Proton affinities of some compounds 
At the end of the drift tube there is an intermediate chamber in which most of the air from the drift tube through a small orifice is pumped away. The ions in the drift tube are extracted and focused by the ion optical lens and finally in a high vacuum chamber are detected by a quadrupole mass spectrometer with ion pulse counting system. The ionic count rates $I\left(\mathrm{H}_{3} \mathrm{O}^{+}\right)$and $I\left(\mathrm{MH}^{+}\right)$are measured in counts per second (CPS), which are proportional to the respective densities of these ions. Although quadrupole mass filter is a traditional analyzer in the current PTR-MS instrument, other MS analyzers have been investigated including time-of-flight (TOF) (Blake, 2004; Ennis, 2005; Jordan, 2009), ion trap (Prazeller, 2003) and linear ion trap mass spectrometer (Mielke, 2008).

Normally, PTR-MS can determine the absolute concentrations of trace VOCs according to well-established ion-molecular reaction kinetics. If trace analyte $\mathrm{M}$ reacts with $\mathrm{H}_{3} \mathrm{O}^{+}$, then the $\mathrm{H}_{3} \mathrm{O}^{+}$signal does not decline significantly and can be deemed to be a constant. Thus, the density of product ions $\left[\mathrm{MH}^{+}\right]$at the end of the drift tube is given in Eq.20 (Lindinger, 1998).

$$
\left[M H^{+}\right]=\left[H_{3} O^{+}\right]_{0}\left(1-\mathrm{e}^{-k[M] t}\right)
$$

Where $\left[\mathrm{H}_{3} \mathrm{O}^{+}\right]_{0}$ is the density of reagent ions at the end of the drift tube in absence of analyte $\mathrm{M}, k$ is the reaction rate constant of reaction (18) and $t$ is the average reaction time the ions spending in the drift tube. In the trace analysis case, $k[\mathrm{M}] t<1$, Eq.(20) can be further deduced to the following form.

$$
[M]=\frac{\left[M H^{+}\right]}{\left[H_{3} O^{+}\right]_{0}} \frac{1}{k t}
$$

Eq.21 is often used in a conventional PTR-MS measurement. However, when the concentration of analyte $\mathrm{M}$ is rather high, the intensity change of reagent ions $\mathrm{H}_{3} \mathrm{O}^{+}$is not ignorable. In this case, the relation $k[\mathrm{M}] t<<1$ is not tenable, therefore the regular Eq.21 is no longer suitable for concentration determination. For a more reliable measurement, the following Eq.22, deduced from Eq.20, can be used to determine the concentration of analyte $\mathrm{M}$. For instance, the concentrations of gaseous cyclohexanone inside the packaging bags of infusion sets were found to be rather high, and its concentrations at several tens of ppm level could be detected according to Eq.22 (Wang Y.J., 2009).

$$
[M]=\ln \frac{\left[\mathrm{H}_{3} \mathrm{O}^{+}\right]_{0}}{\left[\mathrm{H}_{3} \mathrm{O}^{+}\right]_{0}-\left[M H^{+}\right]} \frac{1}{k t}
$$

In PTR-MS instrument, the signal intensities of primary and product ions can be measured. And the reaction time can be derived from the instrument parameters and the reaction rate constant can be found in literatures for most substances or calculated by the theoretical trajectory model (Chesnavich, 1980; Su, 1982) using dipole moment and polarizability. Thus the absolute concentration of trace component can be easily obtained without calibration.

\subsection{Optical scintillation}

The industrial stack gas is one of the major sources of particulate matter and pollution in the atmosphere. With the high speed development of economy, this situation will exist for a 
long time. It plays an important role in the environmental management and pollution control to monitor exhaust gas continuously. Using optical scintillation caused by stack gas flow to measure velocity has greater advantage than some traditional velocity measurement techniques, such as Pitot tube, hot wire anemometry and laser Doppler velocimeter (LDV). However, the corresponding theory is not consummate yet.

A light beam passes through the stack gas flow in an industrial setup, the light intensity will fluctuate due to a variety of reasons. First of all, particles move in or out the view of sight in random will induce optical intensity fluctuations (Chen, 1999 \& 2000; Yuan, 2003). This optical scintillation made by particle concentration statistical fluctuations can only be observed when the view of sight is small, the optical path is short, the particle diameter is large and the concentration is low. Commonly, large size apertures of transmitter and receiver are used to measure optical scintillation in the large stack of factory, this kind of scintillation signals is rarely used for measurements of gas flow velocity. Secondly, in high temperature stack gas flow, the refractive index is affected by the turbulence, and it will fluctuate in both the temporal and spatial domains. The characteristic frequency of scintillation caused by the above two reasons can be expressed as (Ishimaru, 1986; Andrews, 2000):

$$
f \approx \frac{v}{D_{r}}
$$

Where $v$ is the mean velocity, $D_{r}$ is the diameter of the receiver's aperture. If $v=10 \mathrm{~m} / \mathrm{s}$, $D_{r}<1 \mathrm{~mm}$, the characteristic frequency is above $10^{4} \mathrm{~Hz}$. The frequency of optical scintillation caused by turbulence is higher and reaches hundreds or thousands Hz. There has been a technique (Wang, T.I., 2003) which uses the scintillation signals of high frequency caused by refractive index fluctuations to measure velocity of stack gas flow, and the refractive index fluctuations is determined by temperature field gradient. It would be difficult to measure velocity when temperature field distributes uniformly.

The fluctuations of particle concentration field can also cause optical scintillation in low frequency range which is commonly below than tens Hz. In the low frequency part of optical scintillation spectrums, the scintillation intensity shows good linearity with particle concentration. This linearity has been used to measure particle concentration (Клименко, 1984). The low frequency of optical scintillation that caused by stack gas flow is relative to the particle concentration fluctuations at random, and it is an experiential knowledge, but this problem still need further investigations in theory.

The scintillation signals of low frequency caused by particle concentration fluctuations are employed in this research work, and parallel double transceiver technique is adapted to measure the velocity and particle concentration of stack gas flow. In this case, even if the temperature field distributes uniformly and refractive index fluctuation is weak, the velocity and particle concentration could still be measured at the same time. The received optical scintillation signal is analyzed and the result illustrates that the power ratio of optical scintillation spectrum in part of low frequency is $-8 / 3$.

The signals are received in manner of Fig.3. The emitted light beams are divergent spherical waves, and both beams propagate along $x$-axis and their origin are both at $x=0$. The diameter of transmitter aperture is $D_{t}$ and the diameter of the two receivers is $D_{r}$. The distance between transmitter and receiver is $L$, and the distance between the two receivers is $l$.The direction of stack gas flow is $y$ axis, the mean velocity is $v$. The system with two point source trasmitters and two point receivers is discussed here. 


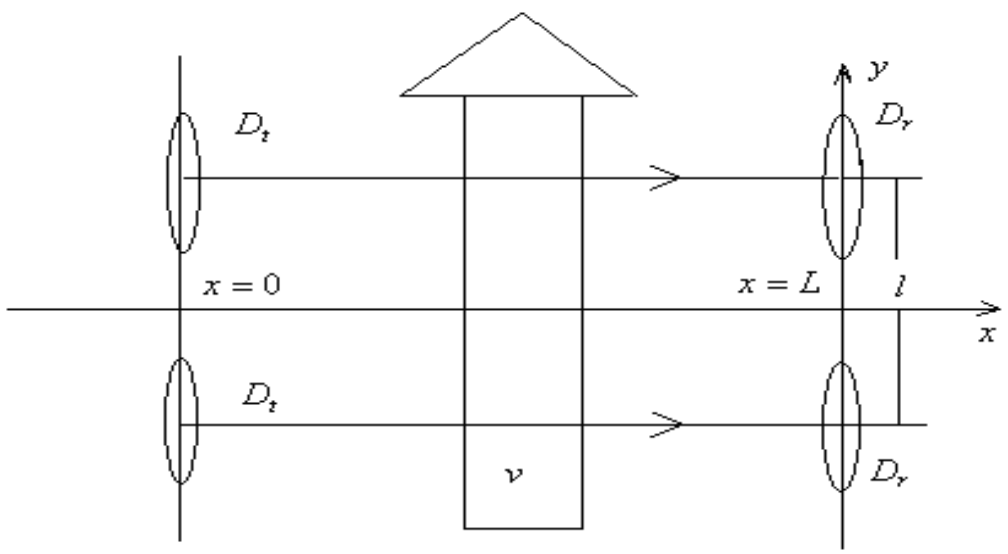

Fig. 3. The layout of optical scintillation measurement

Let the extinction coefficient of stack flow be $\alpha(r, t)$, according to the law of Beer-Lambert, the received logarithmic light intensity is

$$
\ln I(t)=\ln <I>-\int_{0}^{L} \alpha^{\prime}(r, t) d x
$$

where $<\cdot>$ is the assemble average, $\alpha^{\prime}(r, t)$ is the perturbation part.

The cross-correlation function of the two scintillation signals received by two independent receivers can be written as :

$$
C_{\ln I}(r, \rho, t, \tau)=<\int_{0}^{L} \alpha^{\prime}\left(r_{1}, t-\tau\right) d x_{1} \int_{0}^{L} \alpha^{\prime}\left(r_{2}, t\right) d x_{2}>
$$

where $\tau$ is time delay. For homogeneous isotropic time stationary turbulence, the correlation function is only relative to the distance of the two receivers and time delay, then the cross-correlation function is

$$
C_{\ln I}(\rho, \tau)=\int_{0}^{L} \int_{0}^{L} R_{\alpha}\left(r_{1}-r_{2}, \tau\right) d x_{1} d x_{2}
$$

where $R_{\alpha}\left(r_{1}-r_{2}, \tau\right)$ is the correlation function of extinction coefficient. Because of the movement of the stack gas along $y$-axis, according to Taylor frozen turbulence hypothesis, and by the geometric relations shown as Fig.3, we obtain:

$$
R_{\alpha}\left(r_{1}-r_{2}, \tau\right)=R_{\alpha}\left(x_{1}-x_{2}, l-v \tau, 0\right),
$$

Inserting Eq. (27) into Eq. (26), Eq. (26) reduces to

$$
C_{\ln I}(l, \tau)=2 \int_{0}^{L}(L-x) R_{\alpha}(x, l-v \tau) d x
$$


And

$$
R_{\alpha}(x, l-v \tau)=\iint_{0}^{\infty} \int \cos \left(\kappa_{2}(l-v \tau)+\kappa_{1} x\right) \varphi_{\alpha}(\kappa) d \kappa_{1} d \kappa_{2} d \kappa_{3}
$$

where $\varphi_{\alpha}(\kappa)$ is the three-dimensional power spectrum of extinction coefficient fluctuations . For a stationary random process, correlation function can be expressed as

$$
C_{f}(\tau)=\frac{1}{2}\left[D_{f}(\infty)-D_{f}(\tau)\right]
$$

where $f$ is a stationary random function, $D_{f}(\tau)$ is structure function .

The low frequency of optical scintillation caused by stack gas flow is relative to the particle concentration random fluctuations, meanwhile extinction coefficient is linear with particle concentration,

$$
\alpha=K_{m} m,
$$

where $K_{m}$ is the relative extinction coefficient and it is concerned with the particle scale distribution and refractive index, $m$ is particle concentration, the extinction coefficient fluctuations can be expressed as

$$
\alpha^{\prime}=K_{m} m^{\prime},
$$

So we can start from the extinction coefficient fluctuations to discuss the spectrum characteristics of optical scintillation in stack gas flow. Suppose that the particle concentration obeys conservation law and passive scalar quantity, for sufficiently developed turbulence, the extinction coefficient structure function is

$$
D_{\alpha}(r)=C_{\alpha}^{2} r^{2 / 3}, \quad\left(l_{0}<<r<<L_{0}\right)
$$

where $C_{\alpha}^{2}$ is the structure constant of extinction coefficient and $r$ is the distance of two arbitrary points in turbulence field, $l_{0}$ and $L_{0}$ are the inner-scale and out-scale of turbulence, respectively.

Replacing $\infty$ with the out-scale of turbulence $L_{0}$ in Eq. (30), and insert Eq. (33) into Eq. (30), we then obtain :

$$
R_{\alpha}(x, l-v \tau)=\frac{1}{2} C_{\alpha}^{2}\left(L_{0}^{2 / 3}-r^{2 / 3}\right)
$$

where $r=\sqrt{x^{2}+(l-v \tau)^{2}}$, while $r>L_{0}, R_{\alpha}=0$.

Inserting Eq. (34) into Eq. (28),

$$
C_{\ln I}(l, \tau)=C_{\alpha}^{2} \int_{0}^{L}(L-x)\left(L_{0}^{2 / 3}-r^{2 / 3}\right) d x,\left(r=\sqrt{x^{2}+(l-v \tau)^{2}}\right) .
$$

Fig.4 shows the numerical simulation results of Eq. (35). 


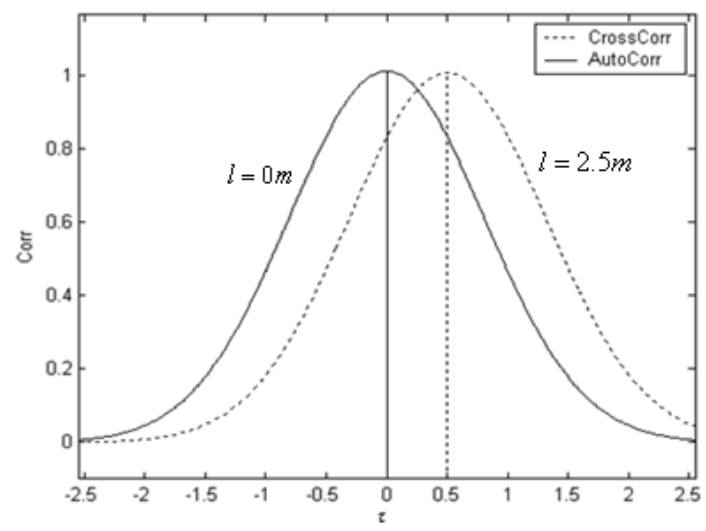

Fig. 4. The numerical computer simulations of Eq. (35). Here $v=5 \mathrm{~m} / \mathrm{s}, L=2 \mathrm{~m}$ and $L_{0}=10 \mathrm{~m}$.

In Fig. 4, the time delay at the peak of the cross-correlation function is $0.5 \mathrm{~s}$, which is equal to $l / v$. So when we know the time delay at the peak of the cross-correlation function, the mean velocity of stack gas flow could be then easily obtained.

The reasons of optical scintillation caused by a light beam passing through stack gas flow are very complex. Particles move in or out the view of sight in random will induce optical intensity fluctuations, but it is hard to obtain the scintillation signals in industrial environment. Turbulence causes the optical scintillation, the frequency of this kind of scintillation commonly reaches hundreds or thousands $\mathrm{Hz}$. Particle concentration fluctuations at random will also induce optical scintillation, and its frequency is commonly lower than hundreds $\mathrm{Hz}$. As demonstrated above, the low frequency part of optical scintillation can be used to measure gas flow velocity and particle concentration simultaneously.

\section{Brief description of the instruments}

\subsection{TDLAS instrument developed for hazard gas online monitoring}

With the features of tunability and narrow line-width of distributed feedback (DFB) laser and by precisely tuning its wavelength to a single isolated absorption line of the target gas, TDLAS technique can be utilized to accurately perform online gas concentration monitoring with very high sensitivity. However, to develop a real practical TDLAS system with high sensitivity and reliability there are many works needed to be done. For instance, signal measurements with a sensitive device inevitably suffer from the predictable or unpredictable sources such as various noises, light intensity fluctuations and laser output wavelength dithers. In order to eliminate or at least reduce the measurement uncertainty and gain better reliability, a close-circle digitalcontrol module (DCM) with functions of digital signal generator, digital lock-in-amplifier (DLIA), data acquisition and processing have been developed.

The single-board DCM is tailored dedicatedly and specially designed for TDLAS applications in which several functions like digital lock-in amplifier, signal generator, data acquisition and processing are all included. In addition, a high precision temperature / current controller board and display board based on ARM 9 are also constructed. With the newly developed DCM, the total amount of PCB needed for a whole TDLAS system has been decreased from the previous 7 independent cards to 3. Moreover, DCM could set 
TEC's parameters through software and a digital interface communicating DCM with TEC. In addition, DCM provides a serial port connecting with a host CPU. The host CPU (MCU or PC) transmits data to DCM setting the parameters, such as frequency, gain, time constant, phase, $1 f$ or $2 f$ selection. The host also receives harmonic signal data from DCM. Since the DCM has synchronized the data acquisition and signal generation, the received data are also packaged in onboard memory with 1024 points each period. Fig.5 is the picture of the developed TDLAS system.
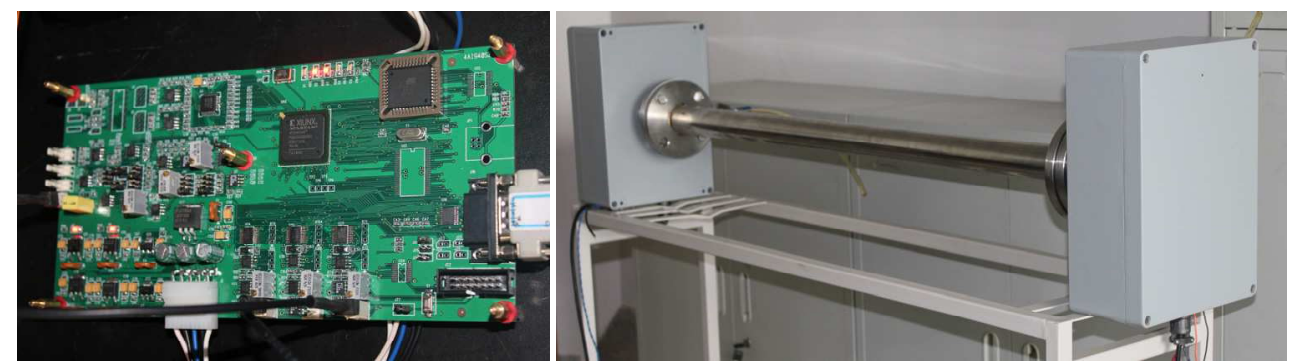

Fig. 5. Developed DCM and TDLAS system for online monitoring of industrial emitted hazard gases.

Though gas analysis based on tunable diode laser absorption spectroscopy (TDLAS) provides features of high sensitivity, fast response and high selectivity. However, many gaseous pollutants with generally low and variable concentrations and large local differences bring challenging requirements to analytical techniques. For example, when the target gas is $\mathrm{CO}$ and its concentration is below a few parts-per-million, the TDLAS system becomes more and more sensitive to noise, interference, drift effects and background changes associated with low level signals. Fig. 6 shows typical second-harmonic absorption signals in detecting low concentration gas of CO under several noises in a practical TDLAS system. In this case it is very necessary to select proper signal processing and digital filtering technique to remove the effects of noise and distortion, and thus to improve the system performance (Xia, 2010). Fig.7 and Fig.8 show the effective signal improvement by employing wavelet transform method choosing proper wavelet basis and decomposition scale.
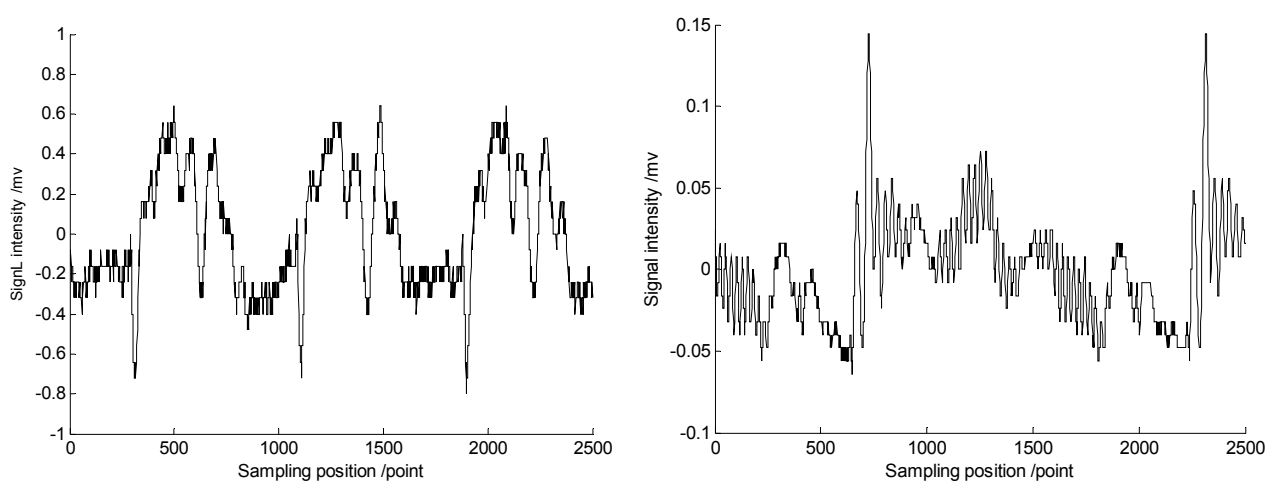

Fig. 6. Typical absorption signals under several noises in a practical TDLAS system. 


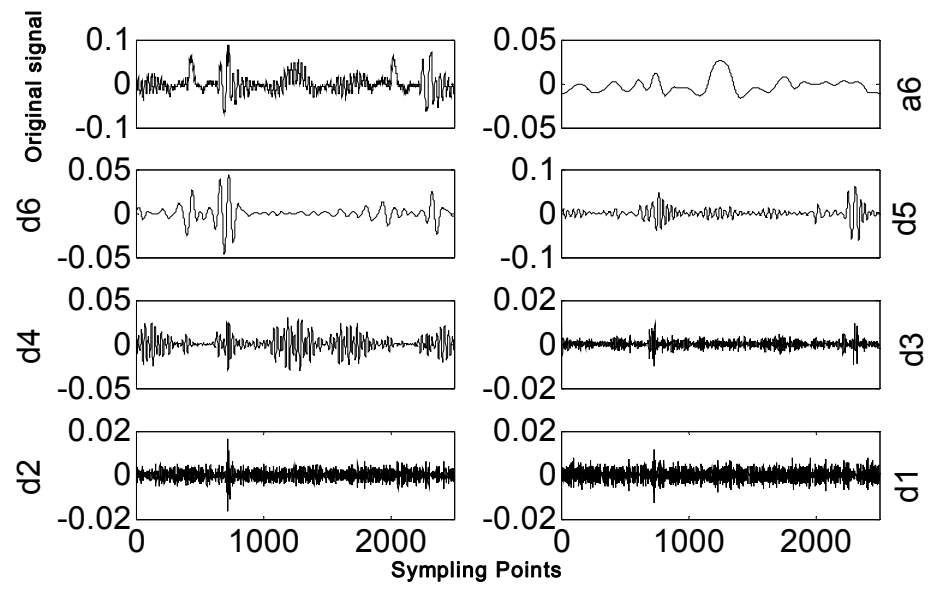

Fig. 7. Signal decompositions at different scales based on wavelet transform.

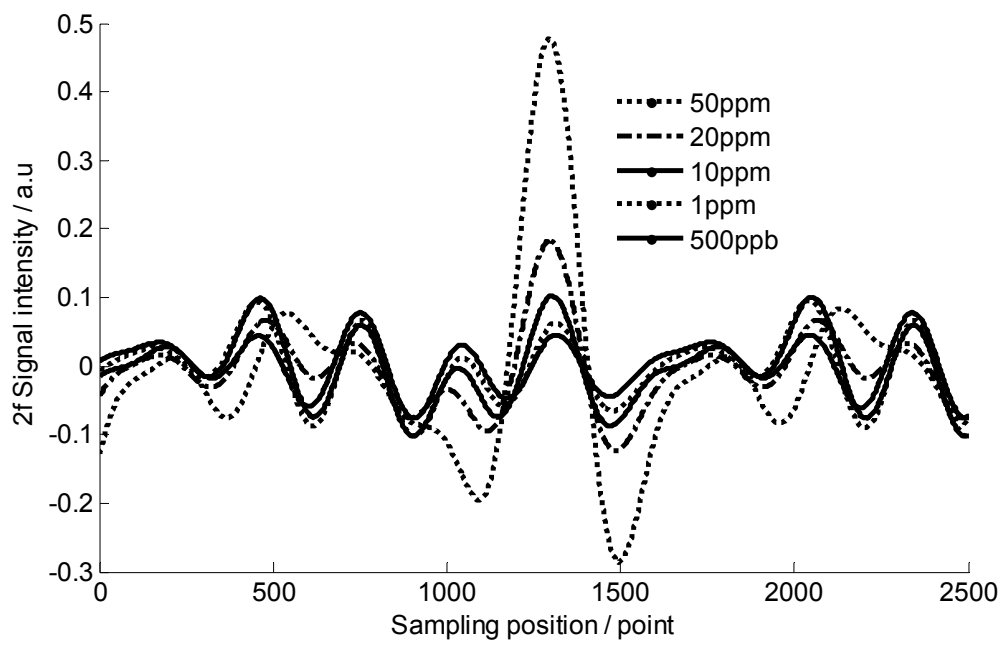

Fig. 8 . The treated $2 \mathrm{f}$ signals after wavelet transform with proper wavelet basis and decomposition scale.

\subsection{PTR-MS instrument constructed for VOCs monitoring}

The widest application of PTR-MS is in the field of atmospheric monitoring. In air, VOCs originate from diverse sources but primarily from biogenic origin. Many VOCs have effects on the sources and sinks of ozone, aerosol formation and climate change. In addition, some VOCs are also toxic to human beings [Monks, 2005], so it is important to monitor their concentrations in a wider environments. Nowadays PTR-MS has been used to detect VOCs from plants, forest, human activities and industry processes. Fig.9 is the picture of the PTRMS instruments we have developed recently for on-line monitoring of industrial emitted VOCs. The left is the standard PTR-MS instrument with detection sensitivity of ppb level. 
The right one is the high sensitive PTR-MS instrument with detection sensitivity of ppt level. Fig.10 shows the experimental results for monitoring of acetone, benzene, acetaldehyde and toluene in laboratory with the developed PTR-MS instrument
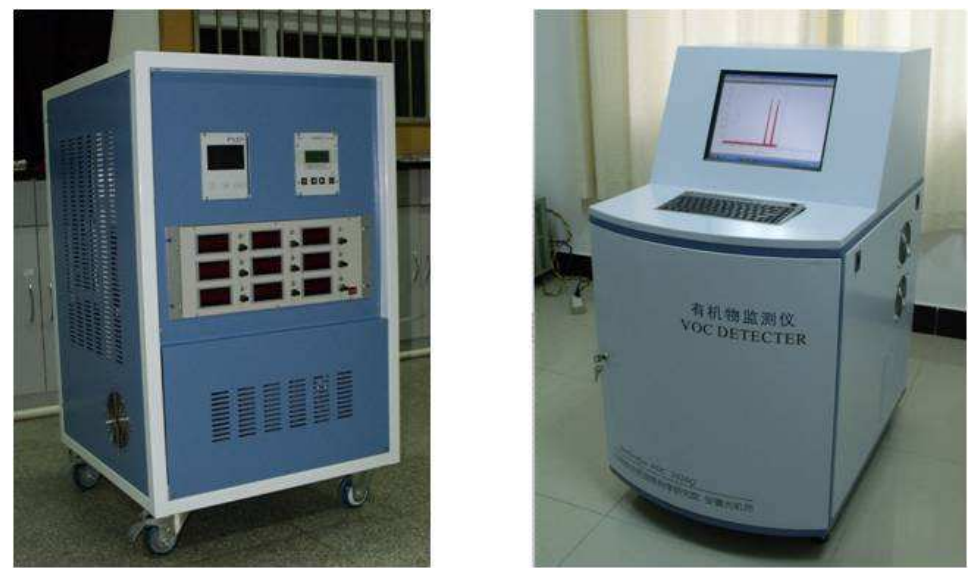

Fig. 9. A series of PTR-MS instruments developed for different requirements.
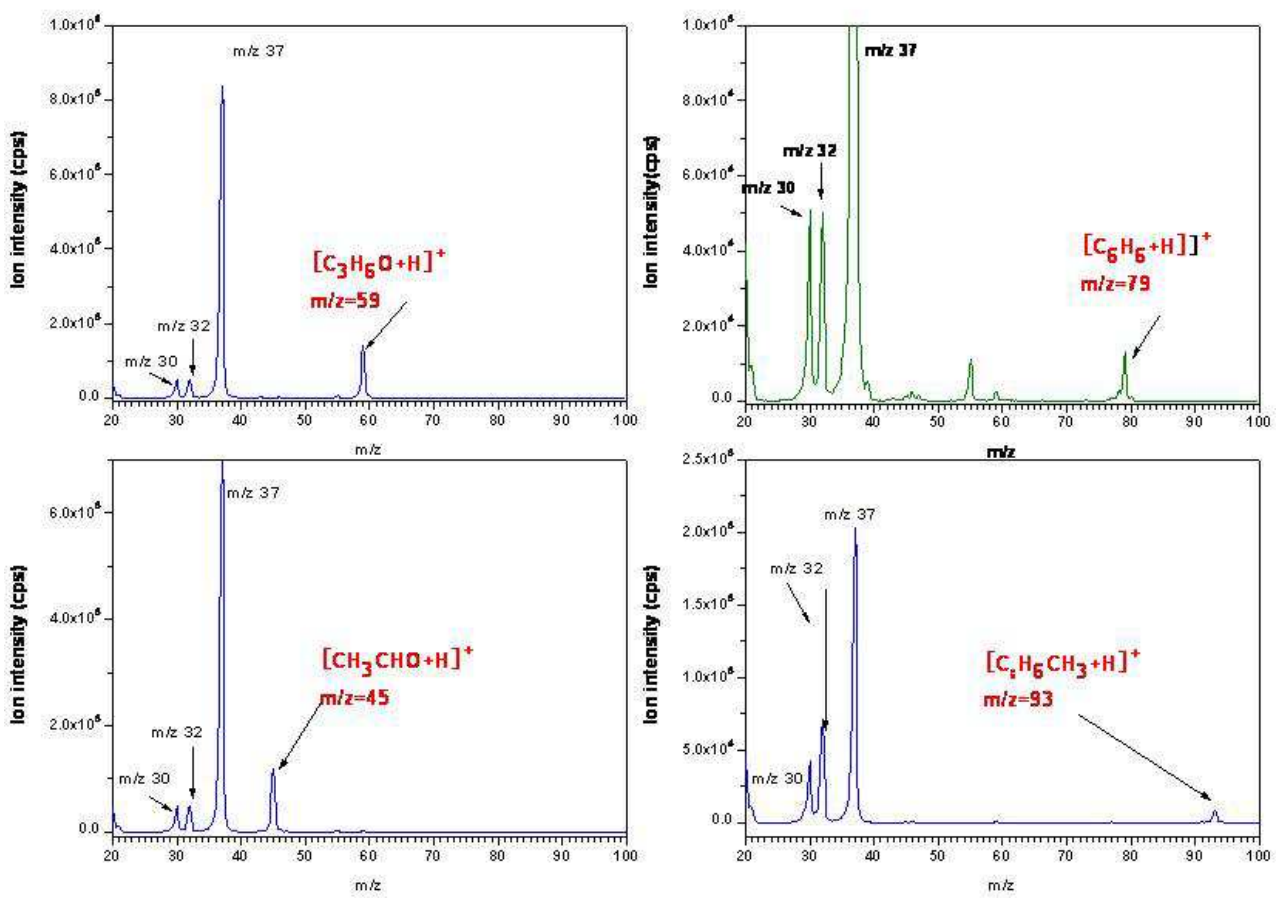

Fig. 10. The measured mass spectra of acetone, benzene, acetaldehyde and toluene in laboratory with the developed PTR-MS instrument. 


\subsection{OSCC instrument developed for gas flow velocity measurement}

In order to measure gas flow velocity in stack, a gas flow velocity sensor was constructed based on the low frequency part of the double-path optical scintillation cross correlation. The schematic diagram of velocity and particle concentration measuring system is shown in Fig.11. Both processed LED light sources emit ideal Gauss spherical waves, the wavelength is $630 \mathrm{~nm}$ and the output power is $1 \mathrm{w}$. The receivers are silicon photoelectric diodes. The received signals will be magnified and filtered by low pass filter, then collected by a A/D card, and finally an industrial computer gets the data to process. Fig.12 shows the developed instruments. The left is the picture of instruments, and the right one is the picture installed on an industrial emission pipe for testing).

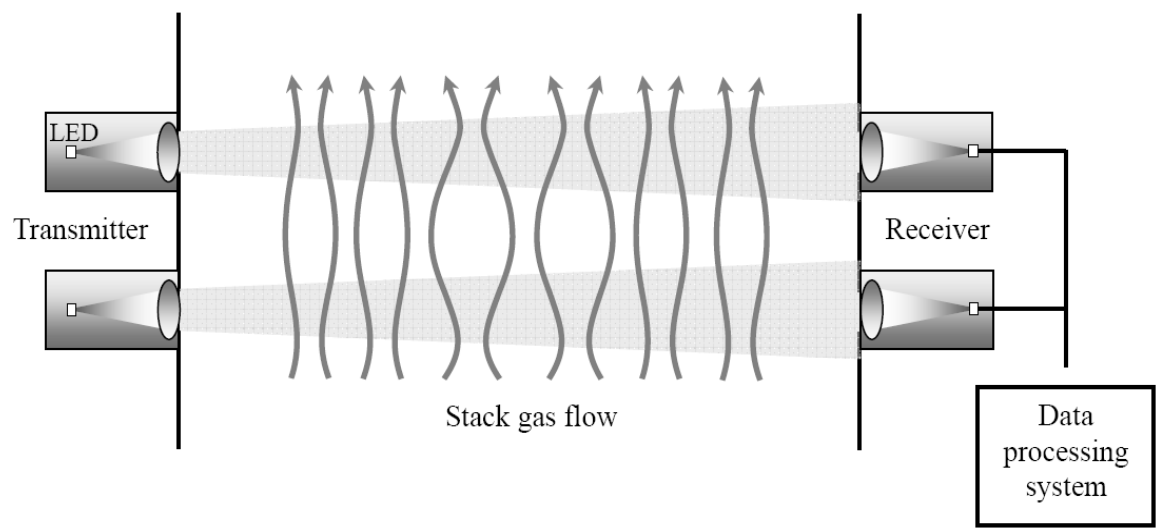

Fig. 11. The schematic diagram of velocity and particle concentration measuring system
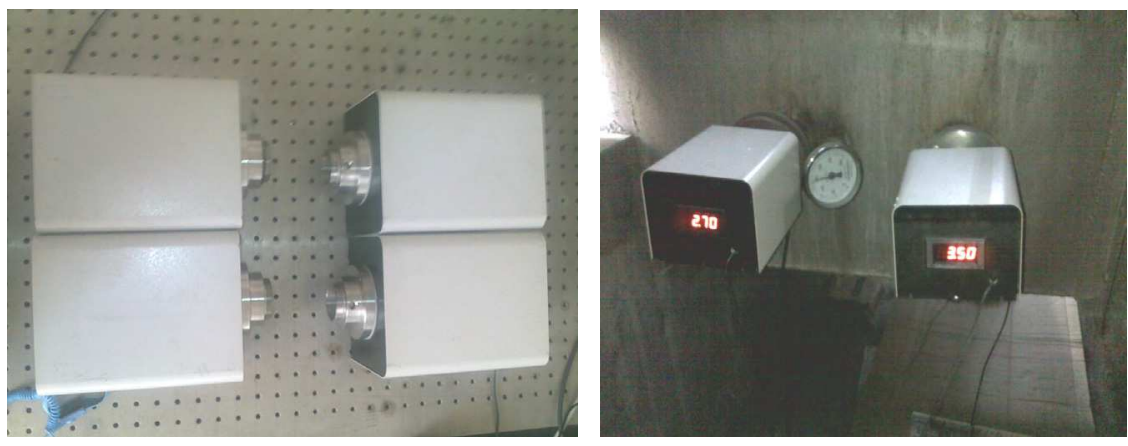

Fig. 12. Developed instrument for online measurements of gas flow velocity.

The field testing measurement was carried out at a chemical factory in Weifang of Shandong province. It is a rectangular stack with the length of $2 \mathrm{~m}$ and the width of $0.55 \mathrm{~m}$. The distance between transmitter and receiver is the length of the stack, and the distance between the two receivers is $0.35 \mathrm{~m}$. The diameters of transmitter aperture and receiver aperture are both $30 \mathrm{~mm}$. (as shown in the right picture of Fig.12). The velocity of the stack gas flow is about $4 \mathrm{~m} / \mathrm{s}$ calibrated with a commercial Pitot tube and the temperature is about $150^{\circ} \mathrm{C}$. The stack gas is produced from the burning of coal. Fig.13 is the received data 
plot from both receivers. Fig.14 shows that the power ratio of the optical scintillation spectrums in part of low frequency is $-8 / 3$.

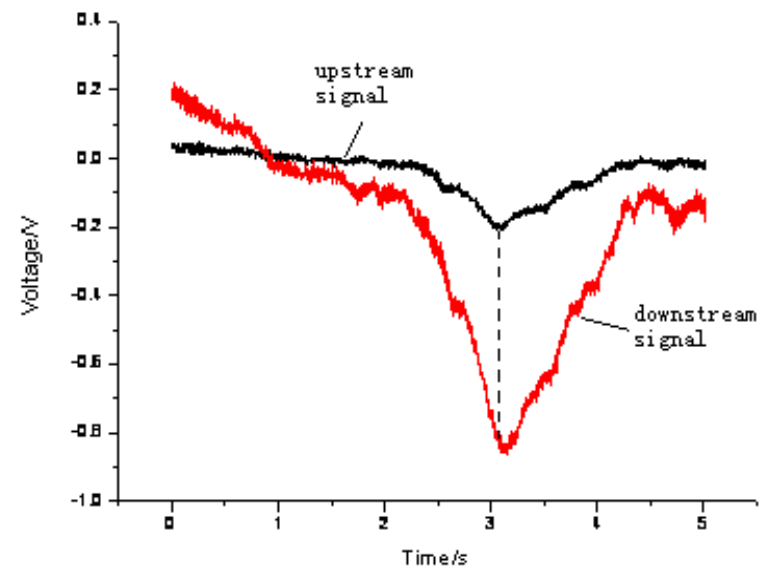

Fig. 13. The received data signal from both receivers

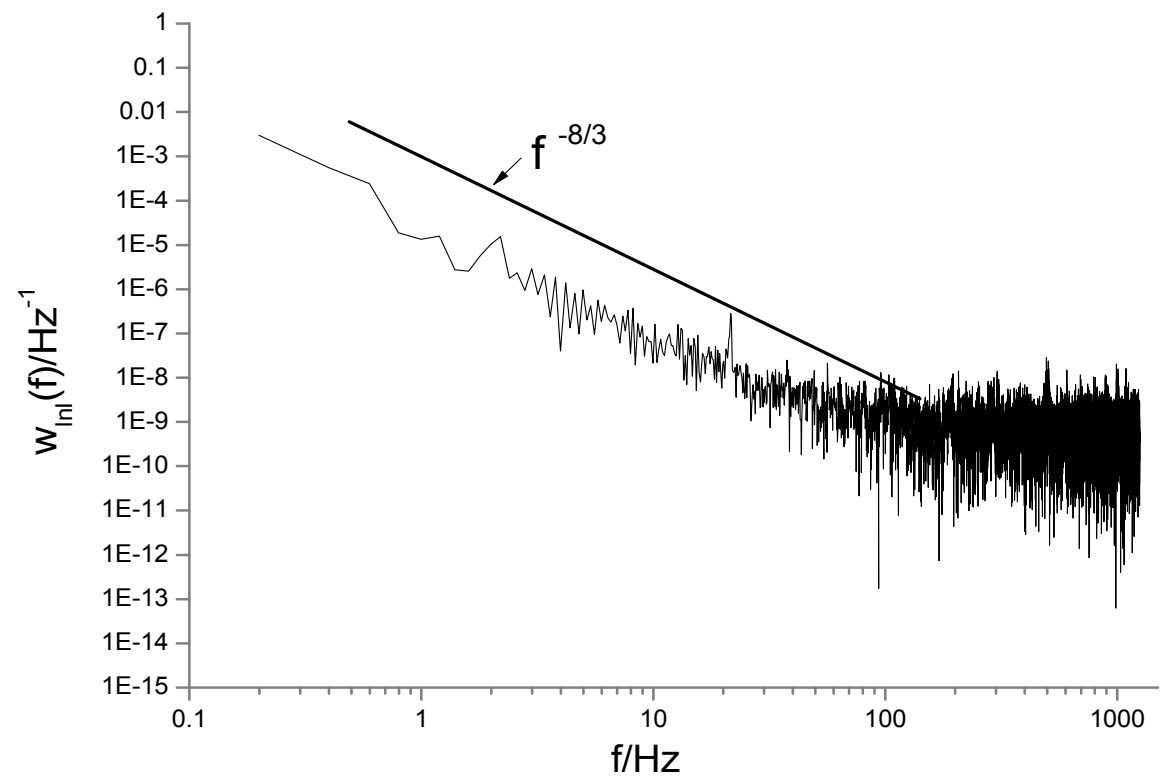

Fig. 14. The low frequency part of optical scintillation spectrum.

The low frequency of optical scintillation caused by stack gas flow is relative to the particle concentration fluctuations at random, the scintillation caused by the fluctuations of particle concentration is analyzed. Fig.15 shows the continuous measurement results of gas flow velocity which shows good agreement comparing with Pitot tube point measurement results. 


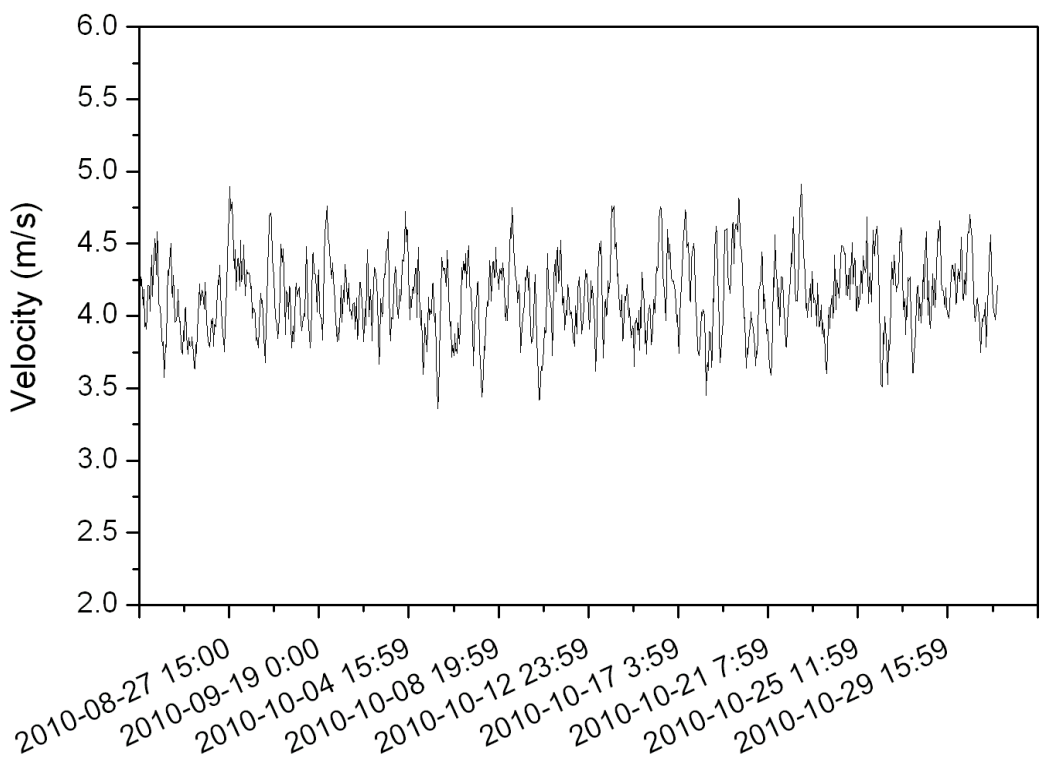

Fig. 15. Continuous measurement results of gas flow velocity with double-path OSCC sensor.

\subsection{Online monitoring of industrial emission gross}

The aim of the project we have carried out during the past few years is to develop a novel system to realize in site real-time monitoring the industrial emission gross. The idea is through on-line measurements of the targeted gas concentrations and gas flow velocity within a stack before emitted to air and plus with help of the theoretical path-weighted function built based on the configuration of stack cross section to gain in situ monitoring of industrial emission gross. Although most works including development of theoretical model and instrument constructions have been fulfilled. However, nowadays it is very hard for us to find a standard commercial instrument to certify the accuracy of our measurements and calculation. Obviously there are still lots of works needed to be further carried out. Here we still use the traditional method to calculate the emission gross presented in the section 4 , i.e.,

$$
F=M \times p \times(S \times v \times C) / R T
$$

Where $\mathrm{F}$ is the emission gross, $\mathrm{M}$ is the molecular weight, $\mathrm{S}$ is the cross section of the stack at the measurement path, $\mathrm{C}$ and $v$ are the measured gas concentration and mean gas flow velocity, respectively.

\section{Experimental results and discussions}

In order to demonstrate the developed instruments, a number of preliminary field trials have been carried out at few sites under different industrial field circumstances as shown in Fig.16 and Fig.17. 


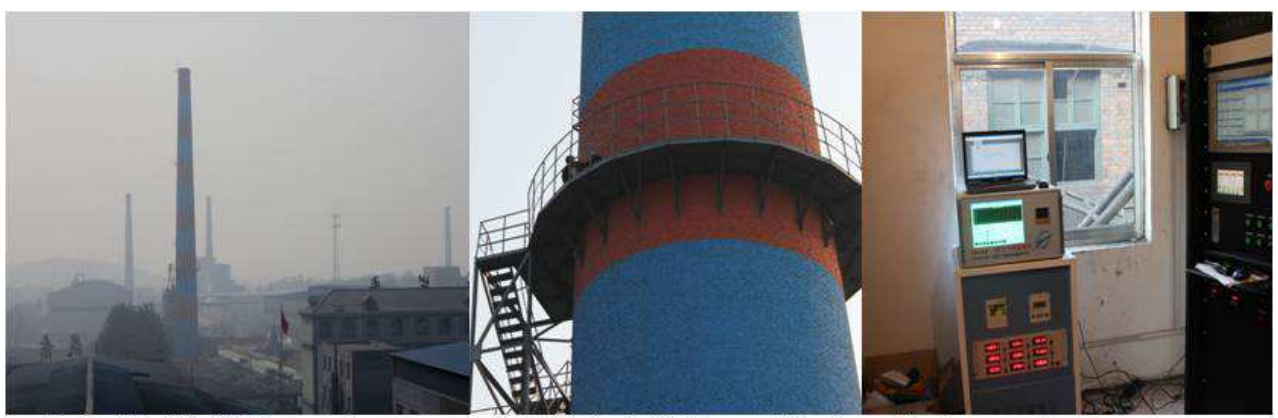

Industrial field circumstance

On-site installation and test

Instrument room

Fig. 16. One of the testing circumstances for in situ on-line monitoring of industrial emissions.

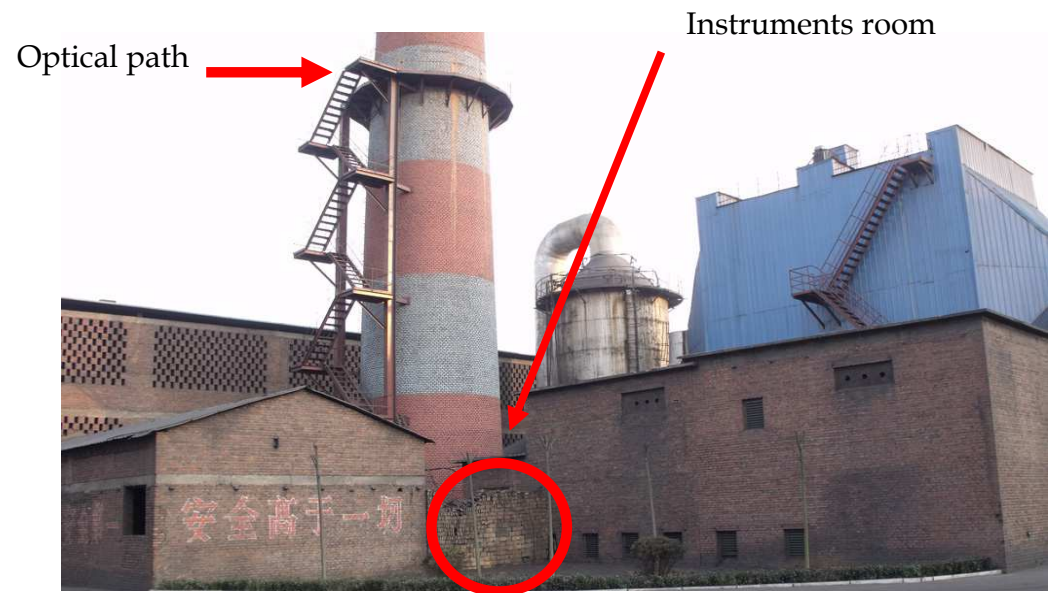

Fig. 17. Another testing place for in situ on-line monitoring of industrial emissions.

Fig.18-21 are the industrial field testing results employing the instruments described in this chapter.
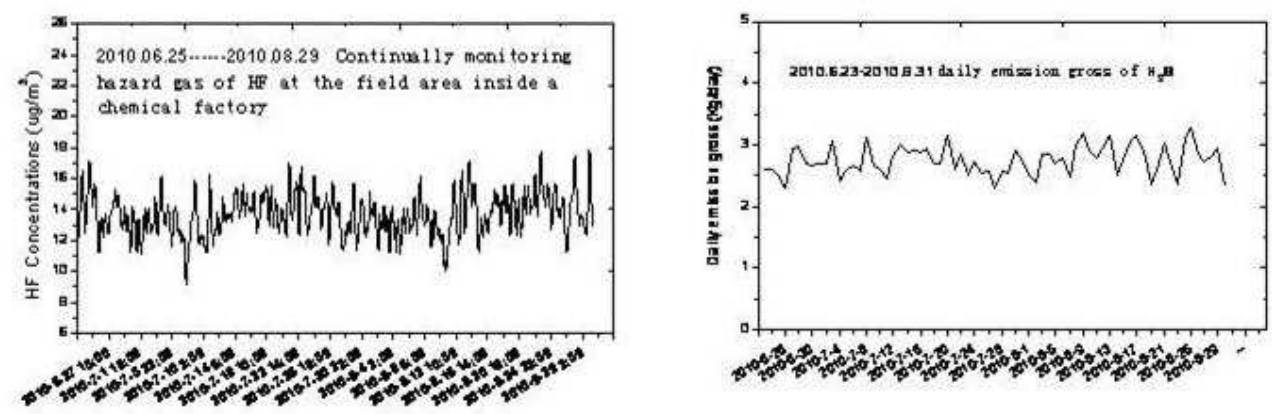

Fig. 18. The continually measurement results of industrial emitted HF and HCI with TDLAS instrument. 


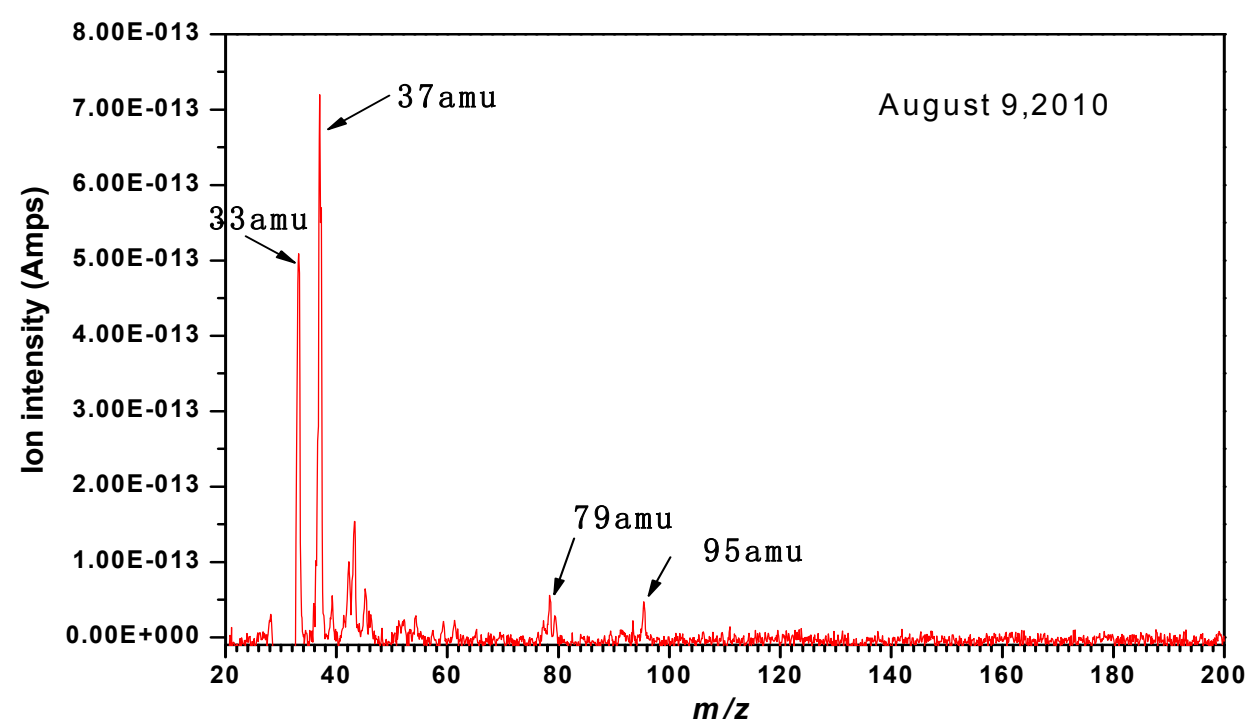

Fig. 19. The total mass scans of VOCs inside the stack measured with PTR-MS

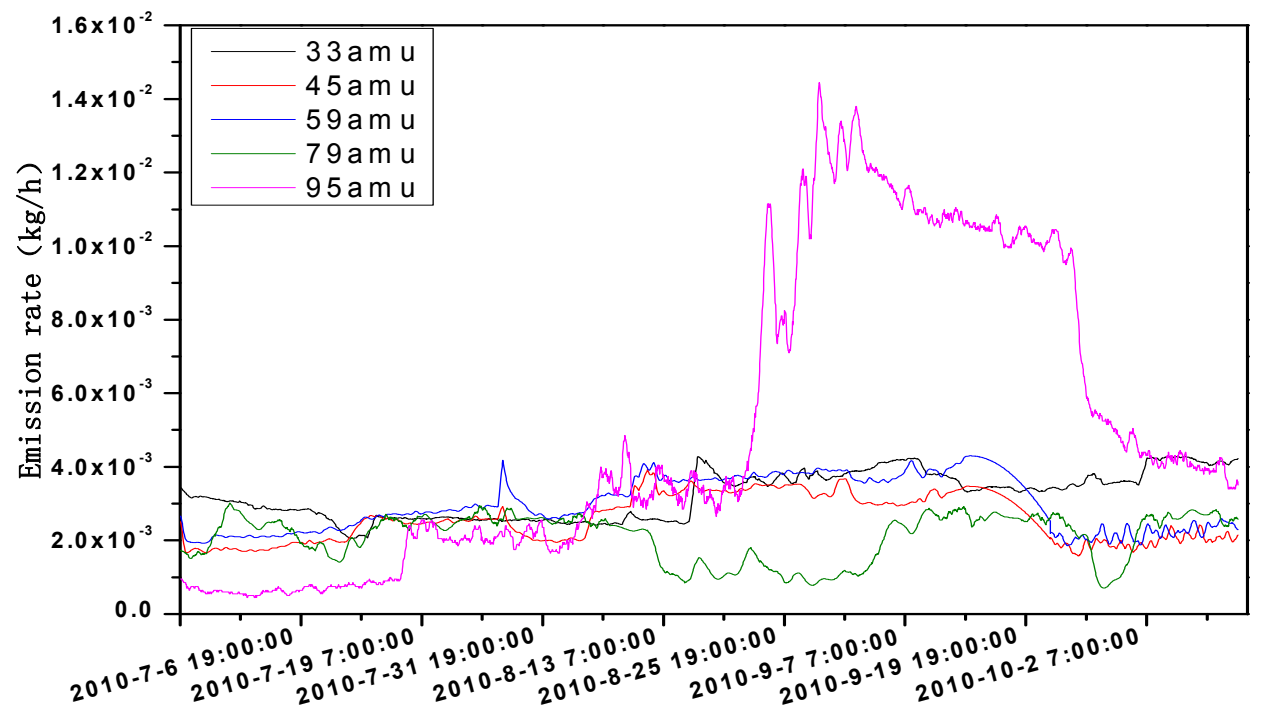

Fig. 20. On-line monitoring results of the VOCs emission rate measured with PTR-MS 

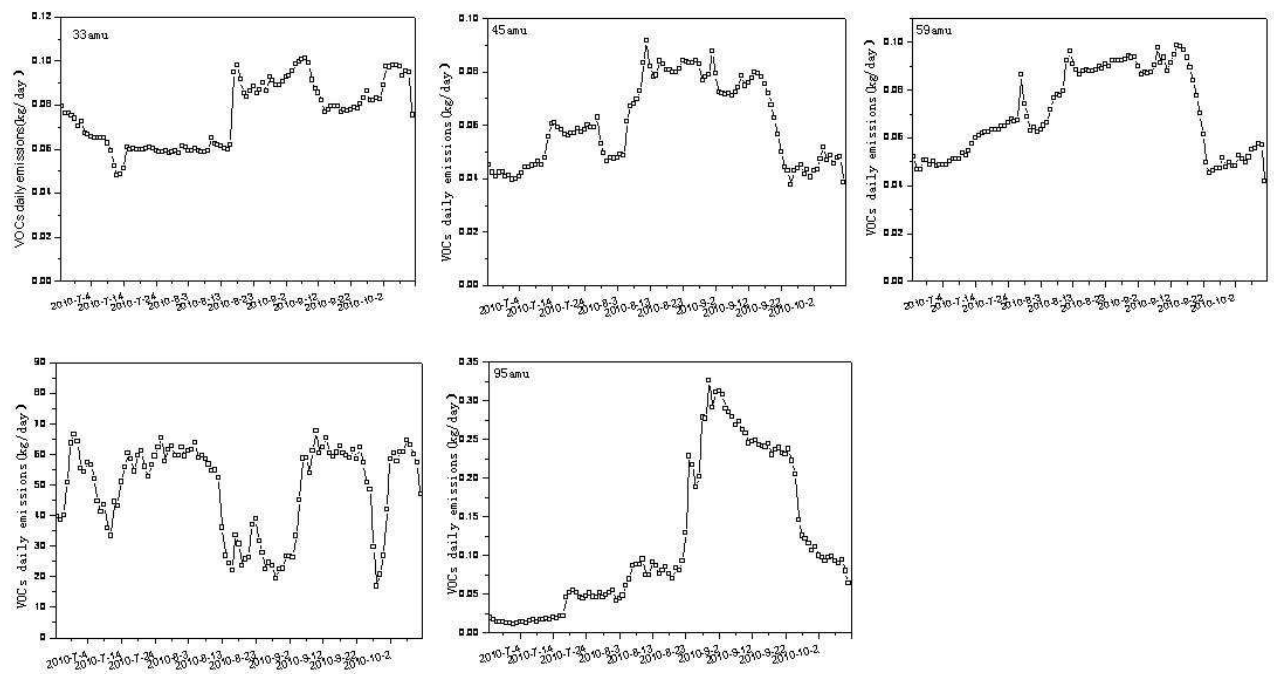

Fig. 21. The measurement results of daily emission gross for VOCs.

\section{Conclusions}

In conclusion, based on TDLAS, PTR-MS and OSCC techniques we have developed a system to monitor a number of industrial hazard gas emissions. However, it should point out here, the measurement results for on-line monitoring the gross of industrial emissions reported here are still in the early stage. Many further works need to be done and will be published in the future. For instance, we have developed a new complex theory based on path-weighted function and the averaged gas flow velocity to calculate the total emissions with the help of gas concentration measurements, however since nowadays there are no any instruments available to certify the measurement accuracy. Therefore in this chapter the common method for calculation of total emissions is still used.

\section{Acknowledgement}

The authors acknowledge the financial support from the National High-tech Research and Development Program of China (Grant No. 2007AA06Z420).

\section{References}

Andrews, L.C.; Phillips, R.L \& Hopen, C.Y. (2000). Aperture averaging of optical scintillations: power fluctuations and the temporal spectrum , Wave Random Media, Vol.10, pp53-70.

Blake, R.S.; Whyte, C.; Hughes, C.O.; Ellis, A.M. \& Monks, P.S. (2004). Demonstration of proton-transfer reaction time-of-flight mass spectrometry for real-time analysis of trace volatile organic compounds. Analytical Chemistry, Vol.76, pp3841-3845. 
Blake, R.S.; Wyche, K.P.; Ellis, A.M. \& Monks P.S. (2006). Chemical ionization reaction timeof-flight mass spectrometry: Multi-reagent analysis for determination of trace gas composition. International Journal of Mass Spectrometry, Vol.254, pp85-93.

Blake, R.S.; Monks, P.S. \& Ellis, A.M. (2009). Proton-transfer reaction mass spectrometry. Chemical Reviews, Vol.109, pp861-896.

Burakov, V.S.; Tarasenko, N.V.; Nedelko, M.I. ; Kononov, V.A.; Vasilev N.N. \& Isakov, S.N. (2009). Analysis of lead and sulfur in environmental samples by double pulse laser induced breakdown spectroscopy, Spectrochimica Acta Part B: Atomic Spectroscopy, Vol.64, No.2, pp141-146.

Cassidy D. T. \& Reid, J. (1982). Harmonic detection with tunable diode lasers two-tone modulation", Appl.Phys.B, Vol.29, pp279-285.

Chen A.S.; Hao, J.M.; Zhou Z.P.; et al (1999). Theoretical solutions for particulate scintillation monitors, Opt. Comm., Vol. 166, pp15-20.

Chen A.S.; Hao, J.M.; Zhou Z.P.; et al (2000). Particulate concentration measured from scattered light fluctuations, Opt. Lett., Vol.25, No.10, pp689-691.

Chen A.S.; Hao, J.M.; Zhou Z.P.; et al (2000). Measuring particulate concentration by means of scattered light scintillation, Proc. Of SPIE, Vol.4222, pp71-75.

Chesnavich, W.J.; Su T. \& Bowers, M.T. (1980). Collisions in a noncentral field: A variational and trajectory investigation of ion--dipole capture. The Journal of Chemical Physics, Vol.72, pp2641-2655.

Christian, T.J.; Kleiss, B.; Yokelson, R.J.; Holzinger, R. ; Crutzen, P.J.; Hao, W.M.; Saharjo, B.H. \& Ward, D.E. (2003) Comprehensive laboratory measurements of biomassburning emissions: 1. Emissions from Indonesian, African, and other fuels, J. Geophys. Res. Atmos., Vol.108, pp4719.

Christian, T.J. ; Kleiss, B. ; Yokelson, R.J. ; Holzinger,R. ; Crutzen, P.J. ; Hao, W.M. ; Shirai,T. \& Blake,D.R. ( 2004 ) Comprehensive laboratory measurements of biomass-burning emissions: First intercomparison of open-path FTIR, PTR-MS, and GC-MS/FID/ECD. J. Geophys. Res. Atmos., Vol.109, pp2311-2319.

Claudia, S.G.; John P.T. \& Dennis, F.R. (2003). Tunable diode laser absorption spectrometer measurements of ambient nitrogen dioxide, nitric acid, formaldehyde, and hydrogen peroxide in Parlier, California. Atmospheric Environment, Vol.37, pp15831591.

Culshaw, B.; Stewart, G.; Dong, F. Z.; Tandy, C. \& Moodie, D. (1998). Fiber optic technique for remote spectroscope methane detection from concept to system realization, Sensors and Actuators B, Vol.51, pp25-37.

D'Amato F.; Mazzinghi, P. \& Castagnoli, F. (2002). Methane analyzer based on TDL's for measurements in the lower stratosphere: design and laboratory tests. Appl.Phys. B, Vol. 75, pp195-202.

de Gouw, J. A. \& Warneke, C. (2007). Measurements of volatile organic compounds in the earth's atmosphere using proton-transfer-reaction mass spectrometry. Mass Spectrometry Reviews, 26, 223-257.

Deguchi, Y.; Noda, M.; Fukuda, Y.; Ichinose, Y.; Endo, Y.; Inada, M.; Abe, Y. \& Iwasaki, S. (2002). Industrial applications of temperature and species concentration monitoring using laser diagonostics. Meas. Sci. Technol., Vol.13, R103-R115. 
Dong F.Z.; Liu W.Q.; Liu J.G.; et al (2005). Online roadside vehicle emissions monitoring (Part 1). Journal of test and Measurement Technology, Vol.19, No.2, pp119-127 (in Chinese).

Dong F.Z.; Liu W.Q.; Liu J.G.; et al (2005). Online roadside vehicle emissions monitoring (Part 2). Journal of test and Measurement Technology, Vol.19, No.3, pp237-244 (in Chinese).

Dupeyrat, G.; Rowe, B.R.; Fahey, D.W. \& Albritton, D.L. (1982). Diagnostic studies of Venturi inlets for flow reactors. International Journal of Mass Spectrometry and Ion Processes, 44, 1-18.

Edner, H. \& Svanberg, S. (1991). Lidar measurements of atmospheric mercury, Water, Air, $\mathcal{E}$ Soil Pollution, 1991(1): pp131-139.

Ennis, C.J.; Reynolds, J.C.; Keely, B.J. \& Carpenter, L.J. (2005). A hollow cathode proton transfer reaction time of flight mass spectrometer. International Journal of Mass Spectrometry, 247, 72-80.

Feher, M. \& Martin T.A. (1995). Tunable diode laser monitoring of atmospheric trace gas constituents. Spectrochim. Acta Part A, Vol.51, pp1579-1599.

Fried, A.; Henry, B. \& Wert, B. (1998). Laboratory, ground-based, and airborne tunable diode laser systems: performance characteristics and applications in atmospheric studies. Appl. Phys. B, Vol.67, pp317-330.

Hansel A.; Jordan A.; Holzinger, R.; Prazeller P.; Vogel W. \& Lindinger W. (1995). Protontransfer reaction mass-spectrometry - online trace gas-analysis at the ppb level. International J. of Mass Spectrometry and Ion Processes, 149/150, 609-619.

Hanson, D.R.; Greenberg, J.; Henry, B.E. \& Kosciuch, E. (2003). Proton transfer reaction mass spectrometry at high drift tube pressure. International J. of Mass Spectrometry, 223, 507-518.

http://www.opticalscientific.com

http://www.cnemc.cn

Inomata, S.;Tanimoto, H.; Aoki, N.; Hirokawa, J. \& Sadanaga Y. (2006). A novel discharge source of hydronium ions for proton transfer reaction ionization: design, characterization, and performance. Rapid Communications in Mass Spectrometry, 20, 1025-1029.

Iseki, T.; Tai H. \& Kimura K. (2000). A portable remote methane sensor using a tunable diode laser. Meas. Sci. Technol. Vol.11, pp594-602.

Ishimaru A. (1986). Wave propagation and scatter in Random medium (Beijing: Science Press), pp674 (in Chinese).

Jin, S.P.; Li, J.Q.; Han, H.Y.; Wang, H.M.; Chu Y.N. \& Zhou S.K. (2007). Proton transfer reaction mass Spectrometry for Online detection of trace volatile organic compounds. Progress in Chemistry, 19, 996-1006.

Jordan, A.; Haidacher, S.; Hanel, G.; Hartungen, E., Herbig, J., Mark, L., Schottkowsky, R., Seehauser, H., Sulzer, P.,Mark, T.D. (2009). An online ultra-high sensitivity protontransfer-reaction mass-spectrometer combined with switchable reagent ion capability (PTR+SRI-MS). International Journal of Mass Spectrometry, Vol.286,pp 3238.

Jordan, A.; Haidacher, S.; Hanel, G.; Hartungen, E.; Mark, L.; Seehauser, H.; Schottkowsky, R.; Sulzer, P. \& Mark, T.D. (2009). A high resolution and high sensitivity proton- 
transfer-reaction time-of-flight mass spectrometer (PTR-TOF-MS). International Journal of Mass Spectrometry, Vol.286, pp122-128.

Kan, R.F.; Liu, W.Q.; Zhang, Y.J.; et al (2006). Large scale gas monitoring with tunable diode laser absorption spectroscopy. Chin. Opt. Lett., Vol.4, No.2, pp116-118.

Kan, R.F.; Liu, W.Q.; Zhang, Y.J.; et al (2007). A high sensitivity spectrometer with tunable diode laser for ambient methane monitoring, Chin. Opt. Lett., Vol.5, No.1, pp54-57.

Karl, T.G.; Christian, T.J.; Yokelson, R.J.; Artaxo, P.; Hao, W.M. \& Guenther, A. (2007). The tropical forest and fire emissions experiment: method evaluation of volatile organic compound emissions measured by PTR-MS, FTIR, and GC from tropical biomass burning. Atmospheric Chemistry and Physics, Vol.7, 5883-5897.

Karl, T.; Apel, E.; Hodzic, A.; Riemer, D.D.; Blake, D.R. \& Wiedinmyer, C. (2009). Emissions of volatile organic compounds inferred from airborne flux measurements over a megacity. Atmospheric Chemistry and Physics, 9, 271-285.

Клименко А.П. (1984). Continuous Monitoring of Dust Concentration (Beijing: China National Defence Industry Press ) pp31-41, pp120 121 (in Chinese).

Lindinger, W.; Hansel, A. \& Jordan A. (1998). On-line monitoring of volatile organic compounds at pptv level by means of proton-transfer-reaction mass spectrometry (PTR-MS) - Medical applications, food control and environmental research. International Journal of Mass Spectrometry, Vol.173, pp191-241.

Linnerud, I.; Kaspersen, P. \& Jæger, T. (1998). Gas monitoring in the process industry using diode laser spectroscopy, Appl. Phys. B, Vol. 67, pp297-305.

Liu, W.Q.; Cui, Z.C. \& Dong, F.Z. (2002). Optical and spectroscopic techniques for environmental pollution monitoring. Optoelectronic technology $\mathcal{E}$ information. Vol.15, No.5, pp1-12.

Liu, W.Q.; Liu, H.L.; Zeng, Z.Y. \& Jiang, Y. (2008). Analysis of spectrum characteristics of optical scintillation in stack gas flow, Chin. Phys., Vol.15, No.8, pp1777-1782.

May, R.D. \& Webster, C.R. (1989). In situ stratospheric measurement of $\mathrm{HNO}_{3}$ and $\mathrm{HC1}$ using the balloon-borne laser in situ sensor tunable diode laser spectrometer. $J$. Geophys. Res., Vol.94, pp16343-16350.

Mielke, L.H.; Erickson, D.E.; McLuckey, S.A.; Muller, M.; Wisthaler, A.; Hansel, A. \& Shepson, P.B. (2008). Development of a proton-transfer reaction-linear ion trap mass spectrometer for quantitative determination of volatile organic compounds. Analytical Chemistry, Vol.80, pp8171-8177.

Mihalcea, R.M.; Webber, M.E.; Baer, D.S.; Hanson, R.K.; Feller, G.S. \& Chapman, W.B. (1998). Diode-laser absorption measurements of $\mathrm{CO}_{2}, \mathrm{H}_{2} \mathrm{O}, \mathrm{N}_{2} \mathrm{O}$, and $\mathrm{NH}_{3}$ near 2.0 um. Appl. Phys. B, Vol.67, pp283-288.

Nadezhdinskii, A.; Berezin, A.; Chemin, S.; et a1 (1999). High sensitivity methane analyzer based on tuned near infrared diode laser. Spectrochimica Acta Part A, Vol.55, pp2083-2089.

Nelson, D. D.; Shorter, J. H.; Mcmanus, J. B. et al. (2002). Sub-part-per-billion detection of nitric oxide in air using a thermoelectrically cooled mid-infrared quantum cascade laser spectrometer. Appl. Phys. B, Vol.75, pp343-350.

NIST Standard Reference Database Number 69, NIST Chemistry webbook, http://webbook.nist.gov/chemistry/.

Platt, U. \& Pemer, D. ( 1980). Direct measurements of atmospheric $\mathrm{CH}_{2} \mathrm{O}, \mathrm{O}_{3}, \mathrm{NO}_{2}$ and $\mathrm{SO}_{2}$ by different optical absorption in the near UV. J. Geophys. Res., 85(C10): 7453 7458. 
Prazeller, P.; Palmer, P.T.; Boscaini, E.; Jobson, T. \& Alexander, M. (2003). Proton transfer reaction ion trap mass spectrometer. Rapid Communications in Mass Spectrometry, 17, 1593-1599.

Reid J.; El-Sherbiny, M. \& Garside, B. K. (1980). Sensitivity limits of a tunable diode spectrometer with application to the detection of NO2 at the 100-ppt level. Appl. Opt., Vol.19, No.19,

Reid J. \& Labrie D. (1981). Second-harmonic detection with tunable diode lasers-Comparison of experiment and theory. Appl. Phys. B, Vol.26, pp203-210.

Rieker, G.B.; Jeffries, J. B. \& Hanson, R.K. (2009). Calibration-free wavelength-modulation spectroscopy for measurements of gas temperature and concentration in harsh environments", Appl. Opt., Vol.48, No.29, pp5546-5560.

Riise H.; Carlisle C.B.; Carr. L.W.; Cooper D. E.; Martinelli R. U. \& Menna R.J. (1994). Design of an open path near infrared diode laser sensor: application to oxygen, water and carbon monoxide. Appl. Opt., Vol.33, pp7059-7066.

Rocco, A.; Natale, G. De; Natale, P. De; et a1 (2004). A diode laser based spectrometer for in situ measurements of volcanic gases. Appl. Phys. B, Vol.78, No.2, pp235-240.

Smith, D. \& Spanel, P. (2005). Selected ion flow tube mass spectrometry (SIFT-MS) for online trace gas analysis. Mass Spectrometry Reviews, 24, 661-700.

Somesfalean, G.; Alnis, J.; Gustafsson, U.; Edner, H. \& Svanberg, S. (2005). Long-path monitoring of $\mathrm{NO}_{2}$ with a $635 \mathrm{~nm}$ diode laser using frequency-modulation spectroscopy, Appl. Opt., Vol.24, pp5184-5188.

Sigrist, M.W., (1994). Air monitoring by spectroscopic Techniques, Published by JOHN WILEY \&SONS, INC.

Somesfalean, G.; Alnis, J.; Gustafsson, U.; Edner, H. \& Svanberg, S. (2005). Long-path monitoring of $\mathrm{NO}_{2}$ with a $635 \mathrm{~nm}$ diode laser using frequency-modulation spectroscopy. Appl. Opt., Vol.24, pp5184-5188.

$\mathrm{Su}, \mathrm{T}$. \& Chesnavich, W.J. (1982). Parametrization of the ion-polar molecule collision rate constant by trajectory calculations. The Journal of Chemical Physics, 76, 5183-5185.

Taatarskii, V. I. (1978). Wave Propagation in a Turbulent Medium (Beijing: Science Press), pp23 (in Chinese)

Taslakov, M.; Simeonov, V.; Froidevaux, M. \& Van den Bergh, H. (2006). Open-path ozone detection by quantum-cascade laser. Appl. Phys. B, Vol.82, No.3, pp501-506.

Uehara, K. \& Tai, H. (1992). Remote detection of methane with 1.66um diode laser. Appl. Opt., Vol.31, No.6, pp809-814.

Wang, F.; Cen, K.F.; Li, N.; Huang, Q. X.; Chao, X.; Yan, J. H. \& Chi. Y. (2010). Simultaneous measurement on gas concentration and particle mass concentration by tunable diode laser, Flow Measurement and Instrumentation, Vol.21, No.3, pp382-387.

Wang J.; Maiorov M.; Baer D.S.; Garbuzov D.Z.; Connolly J.C. \& Hanson R.K. (2000). In situ combustion measurements of $\mathrm{CO}$ with diode-laser absorption near $2.3 \mathrm{um}$. Appl. Opt., 39(30), pp5579-5589.

Wang, T.I.; Ochs, G.R.\& Lawrence, R.S. (1981). Wind measurements by the temporal crosscorrelation of the optical scintillations, Appl. Opt., Vol.20, No.23, pp4073-4081.

Wang, Ting-I (2003). , United States Patent 6,661,319 B2.

Wang, Y.J.; Han, H.Y.; Shen, C.Y.; Li J.Q.; Wang, H.M. \& Chu, Y.N. (2009). Control of solvent use in medical devices by proton transfer reaction mass spectrometry and ion 
molecule reaction mass spectrometry. Journal of Pharmaceutical and Biomedical Analysis, 50, 252-256.

Webber, M.E.; Wang, J.; Sanders, S.T.;. Baer, D.S. \& Hanson R.K. (2000).In situ combustion measurements of $\mathrm{CO}, \mathrm{CO} 2, \mathrm{H}_{2} \mathrm{O}$ and temperature using diode laser absorption sensors. Proc. Comb. Inst.,Vol.28, pp407.

Weibring, P.; Edner, H. \& Svanberg, S. (1998). Monitoring of volcanic sulphur dioxide emissions using differential absorption lidar (DIAL), differential optical absorption spectroscopy (DOAS), and correlation spectroscopy (COSPEC). Appl. Phys. B, Vol.67, No.4, pp 419-426.

Werle P. \& Lechner S. (1996). Recent findings and approaches for suppression of fluctuation and background drifts in tunable diode laser spectroscopy. Proc. Of SPIE, Vol.2834, pp68-78.

Werle, P. (1998). A review of recent advances in semiconductor laser based gas monitors", Spectrochimica Acta Part A, Vol.54, No.2, pp197-236.

Werle P.; Mazzinghi P.; Amato F.D.; et al, (2004). Signal processing and calibration procedures for in situ diode-laser absorption spectroscopy. Spectrochim. Acta Part A, Vol. 60, pp1685-1705.

Wyche, K.P.; Blake, R.S.; Willis, K.A.; Monks, P.S. \& Ellis A.M. (2005). Differentiation of isobaric compounds using chemical ionization reaction mass spectrometry. Rapid Communications in Mass Spectrometry, 19, 3356-3362.

Xia, H.; Dong, F.Z.; Tu, G.J.; et al (2010). High sensitive detection of carbon monoxide based on novel multipass cell , Acta Optica Sinica, Vol.30, No.9, pp2596-2601(in Chinese).

Yuan, Z. F.; Wang, X. D.; Zhou, J.; Pu, X. G. \& Cen, K. F. (2003). Experimental studies on measurement of particle flow velocity using optical scintillation cross-correlations. Thermal Power Generation, Vol.3, pp46-50 (in Chinese).

Zeninari, V.; Parvitte, B.; Joly, L.; Le Barbu, T.; Amarouche, N. \& Durry, G. (2006). Laboratory spectroscopic calibration of infrared tunable laser spectrometers for the in situ sensing of the earth and martian atmospheres. Appl. Phys. B, Vol. 85, pp265272.

Zhang Z.R.; Dong F.Z.; Tu G.J.; et al. (2010). Selection of digital filtering technique in trace gas concentration measurements with tunable diode laser absorption spectroscopy. Journal of Optoelectronics Laser, 2010, 11(21), pp1672-1676(in Chinese).

Zhang Z.R.; Dong F.Z.;Wang Y.; et al (2011). Online monitoring of industrial toxic gases with a digital control module. Acta Optica Sinica, Vol.31, Supplement, s100304.1-6 (in Chinese).

Zhou, X. (2005). Diode-laser absorption sensors for combustion control. Stanford University (Ph. D. thesis). 


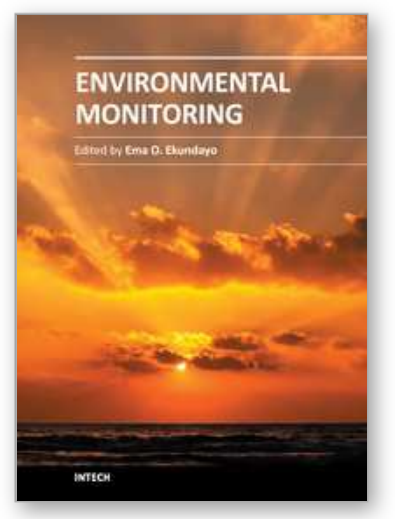

\author{
Environmental Monitoring \\ Edited by Dr Ema Ekundayo
}

ISBN 978-953-307-724-6

Hard cover, 528 pages

Publisher InTech

Published online 04, November, 2011

Published in print edition November, 2011

"Environmental Monitoring" is a book designed by InTech - Open Access Publisher in collaboration with scientists and researchers from all over the world. The book is designed to present recent research advances and developments in the field of environmental monitoring to a global audience of scientists, researchers, environmental educators, administrators, managers, technicians, students, environmental enthusiasts and the general public. The book consists of a series of sections and chapters addressing topics like the monitoring of heavy metal contaminants in varied environments, biolgical monitoring/ecotoxicological studies; and the use of wireless sensor networks/Geosensor webs in environmental monitoring.

\title{
How to reference
}

In order to correctly reference this scholarly work, feel free to copy and paste the following:

F.Z. Dong, W.Q. Liu, Y.N. Chu, J.Q. Li, Z.R. Zhang, Y. Wang, T. Pang, B. Wu, G.J. Tu, H. Xia, Y. Yang, C.Y. Shen, Y.J. Wang, Z.B. Ni and J.G. Liu (2011). Real-Time In Situ Measurements of Industrial Hazardous Gas Concentrations and Their Emission Gross, Environmental Monitoring, Dr Ema Ekundayo (Ed.), ISBN: 978-953307-724-6, InTech, Available from: http://www.intechopen.com/books/environmental-monitoring/real-time-insitu-measurements-of-industrial-hazardous-gas-concentrations-and-their-emission-gross

\section{INTECH}

open science | open minds

\section{InTech Europe}

University Campus STeP Ri

Slavka Krautzeka 83/A

51000 Rijeka, Croatia

Phone: +385 (51) 770447

Fax: +385 (51) 686166

www.intechopen.com

\section{InTech China}

Unit 405, Office Block, Hotel Equatorial Shanghai

No.65, Yan An Road (West), Shanghai, 200040, China

中国上海市延安西路65号上海国际贵都大饭店办公楼405单元

Phone: +86-21-62489820

Fax: $+86-21-62489821$ 
(C) 2011 The Author(s). Licensee IntechOpen. This is an open access article distributed under the terms of the Creative Commons Attribution 3.0 License, which permits unrestricted use, distribution, and reproduction in any medium, provided the original work is properly cited. 